\title{
Estimating the Probability of Leaving Unemployment Using Uncompleted Spells from Repeated Cross-section Data*
}

\author{
Maia Güell \\ Department of Economics \& Business \\ Universitat Pompeu Fabra, \\ CEP (LSE), CEPR and IZA
}

\author{
Luojia $\mathrm{Hu}$ \\ Department of Economics and \\ Institute for Policy Research \\ Northwestern University
}

May 2003

\begin{abstract}
We propose a new econometric estimation method for analyzing the probability of leaving unemployment using uncompleted spells from repeated cross-section data, which can be especially useful when panel data are not available. The proposed method-of-moments-based estimator has two important features: (1) it estimates the exit probability at the individual level and (2) it does not rely on the stationarity assumption of the inflow composition. We illustrate and gauge the performance of the proposed estimator using the Spanish Labor Force Survey data, and analyze the changes in distribution of unemployment between the 1980s and 1990s during a period of labor market reform. We find that the relative probability of leaving unemployment of the short-term unemployed versus the long-term unemployed becomes significantly higher in the 1990s.
\end{abstract}

Keywords: Repeated cross-section data, GMM, Duration analysis, Unemployment. JEL-Classification codes: C41, J64.

\footnotetext{
${ }^{*}$ We would like to thank Joe Altonji, Bo Honoré and Wojciech Olszewski for helpful discussions. We also thank seminar participants at Northwestern University, Purdue University, Universidad Carlos III de Madrid, University of Michigan, Universitat Pompeu Fabra, Univeristy of Western Ontario, Federal Reserve Bank of Chicago, Tinbergen Institute Amsterdam, as well as participants of the Centre for Applied Microeconometrics' workshop on nonlinear dynamic panel data models, the 2002 North American Winter Meeting and the 2002 European Winter Meeting of the Econometric Society for very useful comments. E-mail addresses: maia.guell@econ.upf.es, luojiahu@northwestern.edu.
} 


\section{Introduction}

Since the mid-1970s, European labor markets have suffered from high unemployment rates as well as a high fraction of workers who have been in unemployment for more than 1 year, i.e. the longterm unemployed (see Machin and Manning, 1999). ${ }^{1}$ European labor markets have typically been characterized by a wide use of permanent contracts with high regulated firing costs. In the mid1980s, many European countries introduced fixed-term contracts in order to increase flexibility in the labor market by allowing employers the option of hiring workers under shorter contracts with much lower requirements in terms of firing indemnities. ${ }^{2}$ In this paper, we will analyze the Spanish labor market, which is a striking case in this context. In the mid-80s, Spanish unemployment was around $20 \%$ of the labor force, the highest among OECD countries. Moreover, as many as $52 \%$ of the unemployed were long-term unemployed, also among the highest in the OECD (see figure 1). In 1984, Spain introduced fixed-term contracts in an extreme way compared to other European countries. In particular, while in some countries fixed-term contracts are restricted to some type of workers or sectors, there are no such restrictions in Spain. Firms can use fixed-term contracts repeatedly up to three years. Finally, these new contracts have negligeable firing costs. This implies a very important reduction in labor costs since, among OECD countries, Spain ranks second in terms of strictness of employment protection legislation (see OECD, 1999). ${ }^{3}$

Since their introduction, fixed-term contracts have been widely used and an increasing number of new jobs are fixed-term. ${ }^{4}$ The Spanish labor markets has become more dynamic both in terms of outflows from unemployment to employment, ${ }^{5}$ as well as inflows back to unemployment, partly due to the low rates of renewal of fixed-term contracts into permanent contracts. ${ }^{6}$ During this period of time, there have also been changes regarding participation rates in the labor market. In particular,

\footnotetext{
${ }^{1}$ To give an idea of the magnitude of the problem, in Europe, between 1983 and 1994, almost half of all the unemployed were long-term unemployed, while in the US this proportion was only $9 \%$.

${ }^{2}$ See Grubb and Wells (1993) for a detailed description of fixed-term contracts regulations in Europe.

${ }^{3}$ In Spain, firing a worker for economic reasons costs 20 days' wages per year worked and zero if the worker is fired for disciplinary reasons. However if a case is taken to court and it is declared unfair, it costs 45 days' wages per year worked. As many as $70 \%$ of the cases taken to court are declared unfair (Galdón-Sánchez and Güell, 2000).

${ }^{4}$ Between 1985 and 1994, on average, as many as $94 \%$ of new contracts were temporary contracts.

${ }^{5}$ Outflow rates from unemployment to employment rose from around 6\% in 1984 to around $19 \%$ in 1994 .

${ }^{6}$ Inflow rates from employment to unemployment rose from around $1.5 \%$ in 1984 to around 4.5\% in 1994. Between 1987 and 1994, on average, only $8 \%$ of temporary contracts were transformed into permanent contracts. Also, in this period, more than $60 \%$ of unemployed workers reported that they were unemployed because their temporary contracts had finished.
} 
female labor force participation has risen steadily. ${ }^{7}$ Despite all these changes, a decade after this reform, the unemployment rate remained very much unchanged. However, the share of long-term unemployed has decreased between the mid-80s and early 90s (see figure 1). In this paper, we investigate how this new labor market context could have changed the distribution of unemployment duration for different population groups. The pervasiveness of long-term unemployment has further implications regarding wage, inequality and persistence of unemployment (see Machin and Manning, 1999). From a policy point of view it is also important to understand these changes in order to design more targeted policies.

As pointed out by Machin and Manning (1999), when outflow rates increase at any duration of unemployment, the incidence of long-term unemployment tends to decrease. As explained above, the introduction of fixed-term contracts increased the average outflow rates and this can partly explain the decrease in the share for long-term unemployed, for a given level of unemployment. Also, for a given unemployment rate, to the extend that the increased labor force participation implies an increase in inflows into unemployment, the share of short-term unemployed increases. However, this does not provide a full picture of the changes in the duration distribution of unemployment. In particular, this fact is not informative about how the increased employment chances were distributed among the unemployed workers. This is important since previous studies find strong negative duration dependence in the probability of leaving unemployment. ${ }^{8}$ In this paper, we estimate the probability of leaving unemployment by duration and analyze the relative exit probability between the short-term unemployed and long-term unemployed in order to fully understand the changes in the duration distribution of unemployment.

As with many other countries, panel data are not always available. Panel data from the Spanish Labor Force Survey are available only after 1987. Therefore, to analyze the changes in the probability of leaving unemployment before and after the introduction of fixed-term contracts, we will use the cross-section data drawn from the same survey which is available since 1976. We propose an econometric method that allows us to estimate the probability of leaving unemployment using repeated cross-section data. The most important features of the method are that it estimates the exit probability at the individual level and therefore does not have the small cell problem associated with the grouping approach in the existing previous methods using repeated cross-section

\footnotetext{
${ }^{7}$ Female labor force participation was around $28 \%$ in 1978 and went up to $37 \%$ in 1994 . This increase is concentrated among females between 20 and 55 years old. For males, labor force participation decreased from $76 \%$ in 1978 to $66 \%$ in 1996.

${ }^{8}$ See, for instance, Bover, Arellano and Bentolila (2002).
} 
data (e.g. Sider (1985) and Baker (1992)). Moreover, unlike other methods (e.g. Nickell, 1979), we relax the stationarity assumption on the composition of inflows into unemployment being constant over time. This could be a very strong assumption, specially for some groups of the population such as females. Thus we can use our method to estimate the probability of leaving unemployment for any group of the population.

Our method can be generalized to many empirical applications where either panel data are not available $^{9}$, or the spell of the panel is too short, or attrition in panel data is severe, or in other cases, such as those in which panel data have fewer variables or observations than do cross-section data. ${ }^{10}$ For instance, the Spanish Labor Force Survey releases family characteristics only in the cross-section, but not in the panel format. For this reason, most previous studies of unemployment have focused on men. Our method can therefore be potentially very useful if we are interested in studying female's labor market performances. Lastly, but not the least, the proposed method can also be applied to studies other than unemployment. In fact, the method is applicable for any duration analysis whenever cross section instead of panel data are available, or more suitable (e.g. welfare dependence, employment tenure, etc.).

The rest of the paper is organized as follows. In Section 2, we provide a review of the related econometric literature and then propose an econometric method for estimating the probability of leaving unemployment using repeated cross-section data. Section 3 discusses some extensions of the estimation method. Section 4 presents the data. In section 5, we illustrate and gauge the performance of the proposed estimator by conducting two experiments. In section 6 , we discuss theoretically the possible effects of more dynamic labor markets on the unemployment duration distribution, review the related empirical literature and finally apply the method to the Spanish data to analyze the change in the distribution of unemployment spells before and after the introduction of fixed-term contracts in the mid-80s. Section 7 concludes.

\footnotetext{
${ }^{9}$ For instance, the Labor Force Survey in Italy, Portugal and the US, among others.

${ }^{10}$ See Heckman and Robb (1985) for a discussion of the trade-off of using panel versus repeated cross-sectional data.
} 


\section{Econometric Method}

\subsection{Related Econometrics Literature}

Existing studies that analyze the probability of leaving unemployment typically use two types of data: micro survey data or macro (aggregate) time series data. Studies using micro longitudinal data typically take the standard duration model estimation (see the surveys by Lancaster (1990), van den Berg (2001) and references therein). Micro data have the advantage of providing detailed information on individual characteristics (in particular, the time-varying variables), but also have some drawbacks, for example, they often only cover recent (and thus a relatively short) time span, thus making them inadequate for analyses of historical or cyclical issues. Macro aggregate data, on the other hand, cover a long time span, have no attrition and cover the population, which are more suitable for the latter goal, but they often come at the expense of little or no individual information. Analyses using macro data can, at best, be implemented by some very coarsely defined demographic groups according to the availability of the level of disaggregation in the data (most often, only by gender. See e.g. van den Berg and van Ours (1994, 1996), Abbring, van den Berg and van Ours $(2002)) \cdot{ }^{11}$

A notable exception is a recent paper by van den Berg and van der Klaauw (2001). They propose a method of combining macro (aggregate) administrative data and micro survey longitudinal data to estimate a model of unemployment dynamics. This is an ambitious attempt, but the data requirement is quite stringent, and thus not always feasible (especially when longitudinal micro data are not always available).

Nickell (1979) proposes a method for estimating a duration model that does not require panel data. His model can be estimated simply with a single cross-sectional survey data and historical series on inflows into unemployment. Since the inflow data are often only available at the aggregate level, this method relies on a stationarity assumption that the composition of inflows is constant over time. This could be a very strong assumption, specially for analyzing some economic questions for certain groups of the population.

In this paper, we propose a method that relaxes this strong assumption. This implies that we can study historical questions (as long as some cross-section data are available) as the studies

\footnotetext{
${ }^{11}$ This strand of literature partially deals with this problem by making some functional form assumptions (such as Mixed Proportional Hazard (MPH)) at the individual level but with a calendar time replacing the role of the observed explanatory variables in the traditional micro duration model.
} 
with aggregate data and, moreover, we have individual information. Our method explores multiple (repeated) cross-section data and is based on a synthetic cohort analysis. Some previous studies of unemployment have used these type of data (e.g. Sider (1985) and Baker (1992)). ${ }^{12}$ The main disadvantage with these studies is that the analyses are conducted at the aggregate level, or at best, by some coarsely defined groups (cells). Instead, our method allows us to estimate the probability of leaving unemployment at the individual level. This is not any different from an estimation with panel data in the absence of time-varying covariates and unobserved heterogeneity. Therefore, we avoid the "small cell" problem often encountered in those studies. ${ }^{13}$ For example, the "grouping" method does not work well if there are many explanatory variables, or even with a few explanatory variables, but each has many values (e.g. continuous explanatory variables). When the cell is small, sampling errors can lead to inconsistent estimate of exit probabilities (e.g. greater than one). ${ }^{14}$

Finally, our model, unlike the proportional hazard model, the effect of covariates on the unemployment continuation probability is not proportional. ${ }^{15}$ We will therefore investigate the possibly different changes in duration distributions for different reference workers.

We note that some drawbacks come with repeated cross-section data when compared to the panel. For example, it is harder to deal with unobserved heterogeneity, time-varying regressors and multi-destination problems. We will briefly address some of these issues later in the extension section.

The next subsection presents the estimation method. We start with reviewing some basics of the discrete choice model, and use them to motivate our new estimator in the second subsection.

\footnotetext{
${ }^{12}$ Time series of repeated cross section data have also been used in some other contexts. For example, studies of life cycle consumption and labor supply often use the synthetic cohort approach in which the cohort is constructed by some exogenous characteristics such as the birth year (e.g. Browning, Deaton and Irish (1985), Deaton (1985) and Blundell, Meghir and Neves (1993)). Moffitt (1993) provides a general discussion of estimating a class of dynamic models using repeated cross section. He proposes a regression-based grouping strategy that allows for some general grouping criteria. This paper differs in that our grouping is only by duration, which is an endogenous outcome (staying unemployed). In this sense, our approach is also related to the choice based sampling problem (see, e.g. Manski and Lerman (1977), and Manksi and McFadden (1981)). More discussion on this can be found below.

${ }^{13} \mathrm{~A}$ related estimator (and an alternative to the standard MLE), is the Minimum Chi-square (MCS) estimator (Cockx (1997)). It is also based on the idea of "grouping", but is designed for panel data where individuals are followed over time.

${ }^{14}$ We do need to group duration classes depending on the frequency of the data (see discussion in section 3 ).

${ }^{15}$ See Machin and Manning (1999) for a discussion on the proportional hazard specification.
} 


\subsection{Panel Data and Logit Estimator}

When panel data are available, we can follow individuals over time. Depending on the specific problem, a duration model or a discrete choice model can be used. ${ }^{16}$

To fix ideas, consider two time periods, $t$ and $t+1$. Let $y_{i}=1$ if an unemployed individual $i$ at time $t$ stays unemployed at $t+1$ (or "survives"), and 0 otherwise. Traditionally, we model $y_{i}=1\left\{X_{i} \beta+\varepsilon_{i}>0\right\}$ where $X_{i}$ is a vector of demographic characteristics and $\beta$ is the unknown parameter of interest. Assuming the error term $\varepsilon$ follows a logistic distribution, we have the probability of individual $i$ surviving as $P\left(y_{i}=1\right)=\Lambda\left(X_{i} \beta\right)$ where $\Lambda()=.\exp () /.(1+\exp ()$.$) .$

Maximum likelihood estimator is the solution to

$$
\max _{b} L(b)=\sum_{i} y_{i} \log \Lambda\left(X_{i} b\right)+\left(1-y_{i}\right) \log \left(1-\Lambda\left(X_{i} b\right)\right)
$$

The first order condition is $\sum_{i}\left(y_{i}-\Lambda\left(X_{i} \beta\right)\right) X_{i}=0$, or

$$
\sum_{i} y_{i} X_{i}=\sum_{i} X_{i} \Lambda\left(X_{i} \beta\right)
$$

\subsection{Cross-sectional Data and Method of Moment Estimator}

\subsubsection{Basic Idea: Method of Moments}

Without panel data, we cannot track individuals over time. Thus we cannot directly use the logit estimation since for individual $i$, we do not observe his/her outcome $y_{i}$. The key insight of this paper is based on the synthetic cohort analysis: if the two cross-sectional samples are representative of the underlying population, then the unemployed individuals with duration $s+1$ at time $t+1$ are drawn "from" the same population as those unemployed individuals with duration $s$ at time $t$. Thus although we do not have equation (1) at the individual level, we can mimic this equation by constructing the moment condition from two representative cross-sectional data sets. More specifically, we can construct

$$
\sum_{\substack{d u r=s+1 \\ t+1}} X_{i}=\sum_{\substack{d u r=s \\ t}} X_{i} \Lambda\left(X_{i} \beta\right)
$$

\footnotetext{
${ }^{16}$ The focus of this paper is to model the hazard rate of exiting unemployment, not the transitions between states of employment and unemployment. Moffitt (1993) considers the latter case and discusses how to estimate the Markov model using repeated cross section data.
} 
where the left-hand-side (LHS) is sum over the sample of individuals with duration $s+1$ at time $t+1$ (the "survivors") and the right-hand-side (RHS) is over the sample of individuals with duration $s$ at time $t$. This moment condition defines an estimator of $\beta$.

Consider the simplest example when $X$ includes only a constant and this moment condition defines an estimator of the single coefficient $\beta$. In this case, the LHS of (2) is just the number of the individuals at time $t+1$ who have duration $s+1$, and the RHS is the number of the individuals at time $t$ who have duration $s$ multiplied by the probability of surviving, $\Lambda(\beta)$. Thus the ratio of the two total counts gives the fraction of people who have survived (i.e. stay unemployed) from time $t$ to $t+1$, which is an estimate of the survival probability, $\Lambda(\beta)$. From this we can recover the estimate $\widehat{\beta}$. Similar argument leads to estimation of $\beta$ with general explanatory variables $X$.

Another way to motivate this moment condition, again based on the assumption that each cross-sectional data set is a representative sample randomly drawn from the same population, is by the law of iterated expectation:

$$
E[X \cdot 1(\text { survive })]=E[X \cdot E[1(\text { survive }) \mid X]]=E[X \cdot[P(\text { survive }) \mid X]]
$$

When normalized by the sample size, the LHS of (2) is the sample analogue of $E[X \cdot 1$ (survive)]; and the RHS of (2) is the sample analogue of $E[X \cdot[P$ (survive) $\mid X]]$, where the probability of survival given $X$ is modeled as a Logit.

The method-of-moment estimator based on (2) is somewhat non-standard in that the moments are constructed from two different samples. ${ }^{17}$ To derive the asymptotic variance of the estimator, we can rewrite the moment $(2)$ as

$$
\sum_{t+1} 1\left(d_{i}=s+1\right) X_{i}=\sum_{t} 1\left(d_{i}=s\right) X_{i} \Lambda\left(X_{i} \beta\right)
$$

Then by the standard GMM argument (see, for example, Hansen (1982) and Newey and McFadden

\footnotetext{
${ }^{17}$ Relevant to the current problem is the recent literature on combining data sets (see, for example, Arellano and Meghir (1992), Angrist and Krueger (1992), Lusardi (1996), and Imbens and Lancaster (1994)). These papers typically use data from different (often independent) sources to identify and estimate structural parameters (Arellano and Meghir (1992)), or obtain instrumental variables estimator (Angrist and Krueger (1992) and Lusardi (1996)), or, in the presence of identification from one data source alone, to improve estimation efficiency (Imbens and Lancaster (1994)). Our work is different in that we reply on the same data set, but use samples from different times for identification and estimation. It is thus more in the vein of the synthetic cohort analysis.
} 
(1994)), We have ${ }^{18}$

$$
\begin{aligned}
\sqrt{n_{1}}(\widehat{\beta}-\beta) \simeq & {\left[\frac{1}{n_{1}} \sum_{t} 1\left(d_{i}=s\right) \Lambda\left(X_{i} \beta\right)\left(1-\Lambda\left(X_{i} \beta\right)\right) X_{i} X_{i}^{\prime}\right]^{-1} } \\
& \cdot\left[\sqrt{\frac{n_{2}}{n_{1}}} \frac{1}{\sqrt{n_{2}}} \sum_{t+1} 1\left(d_{i}=s+1\right) X_{i}-\frac{1}{\sqrt{n_{1}}} \sum_{t} 1\left(d_{i}=s\right) X_{i} \Lambda\left(X_{i} \beta\right)\right]
\end{aligned}
$$

where $n_{1}$ and $n_{2}$ are the number of observations of the two samples from time $t$ and $t+1$, respectively.

Let $n_{2}$ be a function of $n_{1}$, i.e. $n_{2}=n_{2}\left(n_{1}\right)$, and let $\alpha=\lim _{n_{1} \rightarrow \infty} \frac{n_{2}}{n_{1}}$.

The first term in the bracket on the right hand side converges to $E\left[1\left(d_{i}=s\right) \Lambda\left(X_{i} \beta\right)\left(1-\Lambda\left(X_{i} \beta\right)\right) X_{i} X_{i}^{\prime}\right]$; and the second term is asymptotically normally distributed with mean zero and variance-covariance $\alpha \cdot \operatorname{Var}\left[1\left(d_{i}=s+1\right) X_{i}\right]+\operatorname{Var}\left[1\left(d_{i}=s\right) X_{i} \Lambda\left(X_{i} \beta\right)\right] .{ }^{19}$ That is,

$$
\sqrt{n_{1}}(\widehat{\beta}-\beta) \rightarrow \mathcal{N}\left(0, A^{-1} B A^{-1}\right)
$$

where

$$
\begin{aligned}
& A=E\left[1\left(d_{i}=s\right) \Lambda\left(X_{i} \beta\right)\left(1-\Lambda\left(X_{i} \beta\right)\right) X_{i} X_{i}^{\prime}\right] \\
& B=\alpha \cdot \operatorname{Var}\left[1\left(d_{i}=s+1\right) X_{i}\right]+\operatorname{Var}\left[1\left(d_{i}=s\right) X_{i} \Lambda\left(X_{i} \beta\right)\right] .
\end{aligned}
$$

The asymptotic variance of $\widehat{\beta}$ is then given by $\operatorname{Avar}(\widehat{\beta})=\frac{1}{n_{1}} A^{-1} B A^{-1}$, and it can be estimated by plugging in a consistent estimate $\widehat{\beta}$ in the sample analogues of $A$ and $B$.

Note that the moment in (2) looks very similar to the FOC of logit in (1). This suggests integrating the moment up with respect to $\beta$ in order to obtain a concave objective function. ${ }^{20}$ More specifically, an objective function is given by

$$
f(b)=\left(\sum_{\substack{d u r=s+1 \\ t+1}} X_{i}\right) b+\sum_{\substack{d u r=s \\ t}} \log \left(1-\Lambda\left(X_{i} b\right)\right)
$$

It can be easily verified that ${ }^{21}$ the FOC of the maximization of (4) corresponds to the moment conditions in (2). Thus the estimator based on the sample moments (2) can be interpreted as an

\footnotetext{
${ }^{18}$ We use the fact that $\frac{\partial \Lambda(a)}{\partial a}=\Lambda(a)(1-\Lambda(a))$.

${ }^{19}$ Here we assume that the two samples are random draws from the same population and thus have same population mean and are independent of each other.

${ }^{20}$ The logit approximation to the probability in the moment conditions makes it easy to recover an objective function. This is not the case for probit since the objective function involves the integral of a normal cdf. Linear probability is not appropriate because there is no guarantee that the predicted probability is between 0 and 1 .

${ }^{21}$ Note $\frac{d \Lambda(a)}{d a}=\Lambda(a)(1-\Lambda(a)) \Rightarrow \frac{d \log \Lambda(a)}{d a}=(1-\Lambda(a)) \Rightarrow \frac{d(1-\log \Lambda(a))}{d a}=-\Lambda(a)$.
} 
M-estimator obtained by maximizing $f(b)$ over $b .^{22}$ The advantage of the M-estimator is that it is often computationally easier (See Appendix B for more detailed discussion).

\subsubsection{Combining Moments and Optimal GMM}

The preceding discussion, based on the transition from duration $s$ to $s+1$, focuses on estimating the effect of the explanatory variables $X$ on the probability of exit unemployment at time $t$. In many cases, we also want to know how this transition probability differs by duration (duration dependence). In fact, the latter is often the primary interest in the traditional duration analysis. This can be easily accommodated in the current framework. Since we do not control for unobserved heterogeneity with the available data, the term duration dependence is used in its loose sense, it can be thought of as a reduced form duration dependence after integrating out unobserved heterogeneity.

One way to implement this is to pool all the data together and add a set of dummy variables, each for a different duration class. In this case, the preceding discussion carries through without modification. The estimates of the parameters associated with the duration dummies can paint a picture of duration dependence, if any.

However, this approach is not efficient. To improve efficiency, we can construct one set of moments like (3) for each of the duration class, $s=1,2, \ldots S$, and optimally combine these moments. We can allow for the intercept to vary by duration class, but restrict the parameters on the rest of $X$ to be the same; the different intercept terms by duration reflect duration dependence.

More specifically, let

$$
g(b)=\left[g_{1}(b)^{\prime}, g_{2}(b)^{\prime} \ldots g_{S}(b)^{\prime}\right]^{\prime}
$$

where

$$
g_{s}(b)=\sum_{t+1} 1\left(d_{i}=s+1\right) X_{i}-\sum_{t} 1\left(d_{i}=s\right) X_{i} \Lambda\left(X_{i} b\right)
$$

and

$$
b=\left(b_{1}^{1}, b_{1}^{2}, \ldots b_{1}^{S}, b_{2}, \ldots b_{k}\right)
$$

${ }^{22}$ Alternatively, we can start with the expected likelihood of the standard logit estimator:

$$
\begin{aligned}
& E[y \log \Lambda(X \beta)+(1-y) \log (1-\Lambda(X \beta))] \\
= & E[\log (1-\Lambda(X \beta))]+E\left[y \log \frac{\Lambda(X \beta)}{1-\Lambda(X \beta)}\right] \\
= & E[\log (1-\Lambda(X \beta))]+E\left[y \log \frac{\exp (X \beta) /(1+\exp (X \beta))}{1 /(1+\exp (X \beta))}\right] \\
= & E[\log (1-\Lambda(X \beta))]+E[y \cdot X \beta] .
\end{aligned}
$$

In the absence of panel data, we can construct sample analogues of the two terms from two cross section samples. 
with $k=\operatorname{dim}(X)$. The GMM estimator $\widehat{\beta}_{g m m}$ is defined as the solution to

$$
\min _{b} g(b)^{\prime} \cdot W \cdot g(b)
$$

where $W$ is a weighting matrix.

The optimal weighting matrix is given by the inverse of the variance-covariance matrix of the moments $V(g(b))$ evaluated at the true parameter value $\beta$, namely, $V(g(\beta))$ where

$$
V(g(\beta))=\left(\begin{array}{cccc}
V_{1}(\beta) & 0 & \cdots & 0 \\
0 & V_{2}(\beta) & \cdots & 0 \\
0 & 0 & \ddots & 0 \\
0 & 0 & \cdots & V_{S}(\beta)
\end{array}\right)
$$

with

$$
V_{s}(\beta)=\alpha \cdot \operatorname{Var}\left[1\left(d_{i}=s+1\right) X_{i}\right]+\operatorname{Var}\left[1\left(d_{i}=s\right) X_{i} \Lambda\left(X_{i} \beta\right)\right]
$$

Therefore by choosing $W=V(g(\beta))^{-1}$, we obtain the optimal GMM estimator,

$$
\widehat{\beta}_{\text {optgmm }}=\arg \min _{b} g(b)^{\prime} \cdot \widehat{V}^{-1} \cdot g(b)
$$

where $\widehat{V}$ is a sample analogue of $V(g(\widehat{\beta}))$ with $\widehat{\beta}$ being a consistent estimator, e.g. $\widehat{\beta}_{g m m}$.

It is straightforward to show that

$$
\sqrt{n_{1}}\left(\widehat{\beta}_{\text {optgmm }}-\beta\right) \rightarrow \mathcal{N}\left(0,\left(\Gamma^{\prime} V^{-1} \Gamma\right)^{-1}\right)
$$

The asymptotic variance-covariance matrix of the optimal GMM estimator is then given by

$$
\operatorname{Avar}\left(\widehat{\beta}_{\text {optgmm }}\right)=\frac{1}{n_{1}}\left(\Gamma^{\prime} V^{-1} \Gamma\right)^{-1}
$$

where

$$
\Gamma(\beta)=\left(\begin{array}{llll}
\Gamma_{1}(\beta), & \Gamma_{2}(\beta), & \cdots & \Gamma_{S}(\beta)
\end{array}\right)^{\prime}
$$

with

$$
\Gamma_{s}(\beta)=E\left[1\left(d_{i}=s\right) \Lambda\left(X_{i} \beta\right)\left(1-\Lambda\left(X_{i} \beta\right)\right) X_{i} X_{i}^{\prime}\right] .
$$

Again, $V_{s}(\beta)$ and $\Gamma_{s}(\beta)$ can be consistently estimated by their sample analogues. For example,

$$
\widehat{\Gamma}_{s}(\beta)=\frac{1}{n_{1}} \sum_{t} 1\left(d_{i}=s\right) \Lambda\left(X_{i} \widehat{\beta}_{g m m}\right)\left(1-\Lambda\left(X_{i} \widehat{\beta}_{g m m}\right)\right) X_{i} X_{i}^{\prime}
$$

and

$$
\widehat{V}_{s}(\beta)=\frac{n_{2}}{n_{1}} \cdot \widehat{\operatorname{Var}}\left[1\left(d_{i}=s+1\right) X_{i}\right]+\widehat{\operatorname{Var}}\left[1\left(d_{i}=s\right) X_{i} \Lambda\left(X_{i} \widehat{\beta}_{g m m}\right)\right]
$$


In order to illustrate this method, in section (5.1) we perform an experiment in which we will compare an estimator from the discrete choice logit model exploring information from panel data and the proposed GMM estimator using two cross-sectional data sets.

\subsection{Alternative Estimation Method}

The method of moment estimator considered above relies on cohort (grouping) by duration, which is an endogenous outcome. To the extent that among the unemployed (with duration $s$ ) at time $t$, we only observe the survivors who "choose" to stay unemployed (i.e. those with duration $s+$ 1 ) at time $t+1$, we can think of this situation as a choice based sampling problem (see, e.g. Manski and Lerman (1977), Manski and McFadden (1981)). Essentially, we have information on the marginal distribution of the individual characteristics $X$ in the unemployed sample at time $t$ and the conditional distribution of $X \mid y=1$ where $y$ is the indicator for staying unemployed at $t+1$. This suggests an alternative estimation strategy using maximum likelihood. For example, we can pool the two unemployed samples (i.e. the sample of unemployed individuals with duration $s$ at time $t$ and the sample of those with duration $s+1$ at $t+1)$ and write down the probability (conditional on $X$ ) that an observation belongs to the second sample.

Specifically, let $m_{1}$ and $m_{2}$ be the number of observations of the first and second sample, respectively. Let $\widetilde{y}$ be an indicator that takes value 1 if an observation belongs to the second sample and 0 if it belongs to the first one. Then the joint distribution of $(X, \widetilde{y})$ from the second sample is

$$
\begin{aligned}
P(X=x, \widetilde{y}=1) & =\frac{m_{2}}{m_{1}+m_{2}} P(X=x \mid y=1) \\
& =\frac{m_{2}}{m_{1}+m_{2}} \frac{P(y=1 \mid X=x) P(X=x)}{P(y=1)}
\end{aligned}
$$

and the joint distribution of $(X, \widetilde{y})$ from the first sample is

$$
P(X=x, \widetilde{y}=0)=\frac{m_{1}}{m_{1}+m_{2}} P(X=x) .
$$

Applying Bayes' rule, we have

$$
\begin{aligned}
P(\widetilde{y}=1 \mid X=x) & =\frac{P(X=x, \widetilde{y}=1)}{P(X=x)}=\frac{P(X=x, \widetilde{y}=1)}{P(X=x, \widetilde{y}=0)+P(X=x, \widetilde{y}=1)} \\
& =\frac{1}{1+\frac{m_{1}}{m_{2}} \frac{P(y=1)}{P(y=1 \mid X=x)}} \\
& =\frac{1}{1+\alpha \frac{1}{P(y=1 \mid X=x)}}
\end{aligned}
$$


where $\alpha=\frac{m_{1}}{m_{2}} P(y=1)$. If $P(y=1)$ is known or can be estimated, $\frac{m_{1}}{m_{2}} P(y=1)$ can be used to essentially re-weight the data. Otherwise, we can treat it as a parameter to be estimated. Assuming a logit specification for $P(y=1 \mid X=x)$, we have

$$
P(\widetilde{y}=1 \mid X=x)=\frac{1}{1+\alpha \frac{1+\exp (x \beta)}{\exp (x \beta)}}=\frac{\exp (x \beta)}{\alpha+(1+\alpha) \exp (x \beta)} .
$$

Maximum likelihood estimation based on (5) yield an estimator of $(\alpha, \beta)$.

In our case, we could construct 2 samples: the first consisting of all unemployed workers with duration 1 to $8+$ quarters at time $t$, and the second one consisting of all unemployed workers with duration 2 to $9+$ quarters at time $t+1$. Following (5), the probability of staying unemployed as a function of duration and other explanatory variables could be estimated. However, as will be discussed below, when duration categories are grouped it is more difficult to proceed with this method. Therefore in the remaining analysis, we only focus on the method of moments approach. In the next section we consider some extensions of our method, starting by the presence of grouped duration data.

\section{Extensions}

\subsection{Grouped Duration Data}

Our method is based on matching different duration categories across different cross sections. Therefore it is important that the frequency of the data matches the grouping of the duration categories. If the grouping of the data coincides with the frequency of the data (say, quarterly duration and quarterly cross sections), then two consecutive cross sections are sufficient to estimate the model. Unfortunately, this is not always the case in practice. For example, in our data, prior to 1987, the reported duration spells can be converted into quarters only in the following way: 1, 2, 3-4, 5-8 and 9 and above (see table $\mathrm{A}$ in the Appendix A). For these data, the moment conditions constructed above will not work. For example, we would like to match the unemployed with duration 2 quarters at time $t-1$ to those with duration 3 quarters at time $t$; but this is not possible in this case because we cannot separately identify the latter (they are grouped with those with duration 4 quarters).

However, our method can be modified to deal with this problem by using more than two cross sections. The main idea is that duration groups at a given cross section can be matched with more disaggregated duration groups from earlier cross sections. For example, in our case, durations of 3 and 4 quarters are lumped together in the data at time $t$. This can be matched with those 
unemployed with duration of 2 quarters at time $t-1$ and those unemployed with duration of 2 quarters at time $t-2$. Assuming that the transition probability between duration 2 and 3 is the same as that between duration 3 and 4, the moment conditions can be modified accordingly. For example,

$$
\sum_{i, t} 1\left\{d_{i}=3,4\right\} X_{i}=\sum_{i, t-1} 1\left\{d_{i}=2\right\} X_{i} \Lambda\left(X_{i} \beta\right)+\sum_{i, t-2} 1\left\{d_{i}=2\right\} X_{i} \Lambda\left(X_{i} \beta\right)^{2}
$$

The same insight can be used to construct moment conditions for estimating the unemployment continuation probability as functions of duration dummies and demographic characteristics $X$ using more than two cross section samples. ${ }^{23}$ Specifically, we can identify four duration dummies from the grouped data structure mentioned above. ${ }^{24}$ More specifically, let $\theta=(\delta, b)$ where $\delta=\left(\delta_{1}, \ldots, \delta_{4}\right)$ are the parameters on the four duration dummy variables, and $\beta$ is a vector of the (common) parameters associated with the demographic variables $X$. Denote $\widetilde{X}_{i} \equiv\left[\begin{array}{cc}1 & X_{i}\end{array}\right]$. Then we can

${ }^{23}$ See Table B in Appendix A for an illustration of this matching.

${ }^{24}$ For the example considered above, an alternative is to match the unemployed individuals with duration 1 and 2 quarters at time $t-2$ with the group of duration 3 and 4 quarters at time $t$. However, to use this matching, we have to impose that the transition probability from 1 to 2 quarters is the same as the transition from 2 to 3 quarters as well as that from 3 to 4 quarters (since we cannot separately identify those with duration 3 and 4 at any given time). Thus this matching is not useful if we are interested in learning about duration dependence. For the same reason, we cannot use the matching of the unemployed with duration 3 and 4 quarters at time $t-3$ and $t-2$ with those with duration 5-8 quarters at time $t$. Instead, we have to use the group with duration 2 quarters from several previous cross sections in order to allow for the transition probabilities to differ between duration categories. 
construct a set of moment conditions $g(\theta)=\left[g_{1}(\theta)^{\prime}, g_{2}(\theta)^{\prime} \ldots g_{4}(\theta)^{\prime}\right]^{\prime}$ where

$$
\begin{aligned}
g_{1}(\theta)= & \sum_{i, t} 1\left\{d_{i}=2\right\} \widetilde{X}_{i}-\sum_{i, t-1} 1\left\{d_{i}=1\right\} \widetilde{X}_{i} \Lambda\left(\delta_{1}+X_{i} b\right) \\
g_{2}(\theta)= & \sum_{i, t} 1\left\{d_{i}=3,4\right\} \widetilde{X}_{i}-\sum_{i, t-1} 1\left\{d_{i}=2\right\} \widetilde{X}_{i} \Lambda\left(\delta_{2}+X_{i} b\right)-\sum_{i, t-2} 1\left\{d_{i}=2\right\} \widetilde{X}_{i} \Lambda\left(\delta_{2}+X_{i} b\right)^{2} \\
g_{3}(\theta)= & \sum_{i, t} 1\left\{d_{i}=5,6,7,8\right\} \widetilde{X}_{i}-\sum_{i, t-3} 1\left\{d_{i}=2\right\} \widetilde{X}_{i} \Lambda\left(\delta_{2}+X_{i} b\right)^{2} \Lambda\left(\delta_{3}+X_{i} b\right) \\
& -\sum_{i, t-4} 1\left\{d_{i}=2\right\} \widetilde{X}_{i} \Lambda\left(\delta_{2}+X_{i} b\right)^{2} \Lambda\left(\delta_{3}+X_{i} b\right)^{2} \\
& -\sum_{i, t-5} 1\left\{d_{i}=2\right\} \widetilde{X}_{i} \Lambda\left(\delta_{2}+X_{i} b\right)^{2} \Lambda\left(\delta_{3}+X_{i} b\right)^{3} \\
& +\sum_{i, t-6} 1\left\{d_{i}=2\right\} \widetilde{X}_{i} \Lambda\left(\delta_{2}+X_{i} b\right)^{2} \Lambda\left(\delta_{3}+X_{i} b\right)^{4} \\
= & \sum_{i, t} 1\left\{d_{i}=9+\right\} \widetilde{X}_{i}-\sum_{i, t-1} 1\left\{d_{i}=9+\right\} \widetilde{X}_{i} \Lambda\left(\delta_{4}+X_{i} b\right) \\
& -\sum_{i, t-7} 1\left\{d_{i}=2\right\} \widetilde{X}_{i} \Lambda\left(\delta_{2}+X_{i} b\right)^{2} \Lambda\left(\delta_{3}+X_{i} b\right)^{4} \Lambda\left(\delta_{4}+X_{i} b\right) .
\end{aligned}
$$

The asymptotic variance of the estimator of $\beta$ and $\delta$ can be derived in a fashion similar to that in the previous discussion. Denote the sample size of the cross sections as $n_{t}, n_{t-1}, \ldots n_{t-7}$, where $n_{t}$ is the number of observations of the sample of time $t$, and $n_{t-1}$ is the number of observations of the sample of time $t-1$, etc. Consider each $n_{t-j}$ as a function of $n_{t}$, for $j=1, \ldots, 7$, and consider asymptotics with $n_{t} \rightarrow \infty$. Denote $\lim _{n_{t} \rightarrow \infty} \frac{n_{t-j}}{n_{t}}=\alpha_{j}$ for $j=1, \ldots 7$. We can implement the optimal GMM by using the inverse of the variance of the moments as the weighting matrix. Again, the variance matrix is diagonal. As an example, we calculate the variance of the first element. The moment condition, after normalized by the sample size $n_{t}$, becomes

$$
g_{1}(\theta)=\frac{1}{n_{t}} \sum_{i, t} 1\left\{d_{i}=2\right\} \widetilde{X}_{i}-\frac{n_{t-1}}{n_{t}} \frac{1}{n_{t-1}} \sum_{i, t-1} 1\left\{d_{i}=1\right\} \widetilde{X}_{i} \Lambda\left(\delta_{1}+X_{i} \beta\right)
$$

Then we have

$$
\begin{aligned}
\sqrt{n_{t}} g_{1}(\theta) & =\frac{1}{\sqrt{n_{t}}} \sum_{i, t} 1\left\{d_{i}=2\right\} \widetilde{X}_{i}-\sqrt{\frac{n_{t-1}}{n_{t}}} \frac{1}{\sqrt{n_{t-1}}} \sum_{i, t-1} 1\left\{d_{i}=1\right\} \widetilde{X}_{i} \Lambda\left(\delta_{1}+X_{i} \beta\right) \\
& \rightarrow N\left(0, V_{t}+\alpha_{1} V_{t-1}\right)
\end{aligned}
$$

where $V_{t} \equiv \operatorname{Var}\left(1\left\{d_{i}=2\right\} \widetilde{X}_{i}\right)$ and $V_{t-1} \equiv \operatorname{Var}\left(1\left\{d_{i}=1\right\} \widetilde{X}_{i} \Lambda\left(\delta_{1}+X_{i} \beta\right)\right)$.

To investigate whether the multi-cross section matching using grouped duration data generates reliable estimates, in section (5.2) we conduct another experiment in which we compare the estimation from 2 cross sections and multiple-cross sections. 


\subsection{Time varying covariates}

The model considered so far includes only time invariant covariates. ${ }^{25}$ We can extend the method to estimate models with individual time-varying regressors. That is, we can estimate the effect of regressors at time $t$ which do not necessarily take the same value at $t-1 .^{26}$ Examples of timevarying regressors include the local unemployment rates or the receipt of unemployment insurance (UI).

Some of these variables can create problems because they are often endogenous to the duration variable. For example, assume the probability of leaving unemployment from duration $s$ in time $t$ depends on $X=\left(X_{1}, X_{2}\right)$ where $X_{1}$ is a vector of time-invariant regressors (such as education, marital status, etc.) and $X_{2}$ is a time-varying regressor (e.g. whether receiving UI at duration $\left.s\right) .{ }^{27}$ Since the receipt of UI depends on duration, we cannot use it to construct the moment conditions as in (2) and the model is under-identified. If there exists an exogenous time-invariant instrument, $Z$, the moment conditions can be easily modified:

$$
\sum_{t+1}\left[\begin{array}{c}
1\left(d_{i}=s+1\right) X_{1 i} \\
1\left(d_{i}=s+1\right) Z_{i}
\end{array}\right]=\sum_{t}\left[\begin{array}{c}
1\left(d_{i}=s\right) X_{1 i} \Lambda\left(X_{i} \beta\right) \\
1\left(d_{i}=s\right) Z_{i} \Lambda\left(X_{i} \beta\right)
\end{array}\right]
$$

Of course, in practice, this kind of instruments can be hard to come by. ${ }^{28}$ However, even in the absence of such instruments, we can explore the multiple duration classes for identification. For example, we can construct a set of moments $g(b)=\left[g_{1}(b)^{\prime}, g_{2}(b)^{\prime} \ldots g_{S}(b)^{\prime}\right]^{\prime}$ where

$$
g_{s}(b)=\sum_{t+1} 1\left(d_{i}=s+1\right) X_{1 i}-\sum_{t} 1\left(d_{i}=s\right) X_{1 i} \Lambda\left(X_{i} \beta\right)
$$

If we restrict some of the parameters on $X$ to be the same across duration classes, we will have a system where the number of moments is greater than the number of parameters to be estimated.

\footnotetext{
${ }^{25}$ Age is time varying; however, the model estimated above includes only a set of 10-year age interval dummies. To the extent that there is little change in those variables between two consecutive quarters, these age dummies can be thought of time-invariant.

${ }^{26}$ Note that this is not considering time-varying regressors in the traditional sense from the duration models where the entire path of these regressors can be incorporated in the likelihood function.

${ }^{27}$ For ease of discussion, here we assume that the duration data are not grouped.

${ }^{28}$ In the case of $X_{2}$ being the local unemployment rate, $Z$ can be the province the unemployed is searching for work. To the extend that workers do not change province over time, then this is a valid time-invariant instrument.
} 


\section{Data}

The data we use is the Spanish Labor Force Survey (Encuesta de la Población Activa, EPA), which is carried out quarterly on a sample of some 60,000 households. ${ }^{29}$ It is designed to be representative of the total Spanish population and contains very detailed information about the labor force status of individuals. Available data starts in the third quarter of 1976 and from the second quarter of 1987 it was redesigned to follow individuals for six consecutive quarters (a rotating panel). ${ }^{30}$ The cross-sectional data contains more information than the released rotating panel, such as household variables.

All the unemployed people in the survey are asked how long they have been looking for a job. This search time will be used as the individual's uncompleted duration of unemployment. Our sample contains data of all unemployed who answered this search question. We exclude those aged 65 or older because transitions to non-employment are more likely for this group. We also exclude those younger than 20 years old to concentrate on workers that have completed full-time education. ${ }^{31}$. We exclude those unemployed that report being retired and disabled workers. This gives us our basic sample of all the unemployed workers.

We will analyze the probability of staying unemployed in the second quarter of every year. We will estimate separate models for the years before and after the 1984 reform. The sample before the reform covers the years 1978 to 1984 and the sample after the reform covers the years 1985 to 1994. ${ }^{32}$ Tables 1a, 1b and 1c provide summary statistics for pooled sample as well as the sample of unemployed workers with previous experience and first job seekers, respectively. The left panel in each table corresponds to the years before the reform and the right corresponds to the years after the reform. Within each panel the two columns correspond to the second quarter and previous quarters. The explanatory variables include age, marital status, education, number of kids in the

\footnotetext{
${ }^{29}$ For a more detailed description, see: http://www.ine.es/dacoin/dacoinme/inotepa.htm

${ }^{30}$ One implication of the rotating panel structure is that in each quarter one sixth of the sample was replaced by new individuals and the rest (5/6) of the sample are repeated observations. Thus the cross-sections after 1987 are not strictly independent. However, with only cross section data, we cannot identify those individuals with repeated observations and thus cannot compute the covariance between the variables from the two different sample. The standard error of the GMM estimator calculated under the independent assumption will therefore be overestimated.

${ }^{31}$ Before 1987 there is not enough information to identify full-time students. For both men and women, labor force participation decreases for workers less than 20 years old over the period of time analyzed.

${ }^{32}$ In 1994 a second reform took effect that restricted the use of fixed-term contracts. We focus on the period before 1994 in order to capture the effects of increased outflows from 1984.
} 
household (aged less than 16 years old) and number of working adults in the household. ${ }^{33}$

\section{Experiments}

\subsection{First Experiment}

We first illustrate the proposed estimation method and examine its performance by an experiment comparing our method with panel data estimates for a recent year for which both data are available. We conduct the following experiment. We take a sample of unemployed individuals in $t$ and follow them to the next quarter $t+1$. So we have a genuine panel. We then artificially generate two crosssectional data sets from this panel. Define a binary variable survive which equals 1 if an unemployed individual who had unemployment spell $s$ in $t$ remains unemployed and reported duration $s+1$ in $t+1$, and 0 otherwise. We then estimate the probability of leaving unemployment using two methods: a discrete choice logit model using the panel on the one hand, and the proposed GMM estimator using the two cross-sectional data sets on the other. Given the same data source and the same model, we would expect the two methods to yield similar estimates.

We chose the sample of unemployed men from the first quarter of 1988 . Table 2 reports the summary statistics. We consider a very simple model specification. The explanatory variables include 3 age dummies (the omitted category is age 20-24), an education dummy for secondary education and above, and a dummy for married. For the year 1988, given that the frequency of the data is quarterly, we have to group the duration by quarter. This generates 9 classes with the last one including 9 quarters and above (top-coded). To avoid small sample size in some duration categories (mainly due to "heaping" in reporting), we further group durations into 5 categories. ${ }^{34}$

Table 3 reports the results for the experiment. Logit estimates are reported in the left panel of the table and the GMM estimates using the two cross-sections are reported in the right panel of the table. Logit estimation using the panel is straightforward, and we therefore focus our discussion on the GMM estimates from the two cross-section data. First of all, the GMM estimates are similar to the panel logit estimates. They have the same signs and the magnitude is comparable. Secondly,

\footnotetext{
${ }^{33}$ Unfortunately, the Spanish LFS does not have data on recipients of unemployment insurance (UI) until 1987. For this reason we do not consider it in the analysis.. The important thing for our goal is there were only minor changes in the UI during the period of time analyzed (see Güell, 2001, for more details).

${ }^{34}$ These 5 categories have different length so that each group has roughly similar number of observations. The top-coded category can be dealt with by linking the group of duration 8 quarters and above in 1988:1 to the group with 9 quarters and above in 1988:2.
} 
the standard errors of the GMM estimates are larger than those of the panel estimates. This is not completely surprising since panel logit (MLE) is the efficient estimator for the same model. Overall, the experiment suggests that our estimator performs reasonably well.

As for the interpretation of the results, there is some evidence suggesting negative duration dependence. Note that what is modelled here is the unemployment continuation probability, so the fact that the estimates on the duration dummies are monotonically increasing implies that the longer an individual is unemployed, the less likely he or she will leave unemployment, which corresponds to the negative duration dependence in the traditional micro duration model.

It is worth noting that in our method, the grouping of the duration variable should match with the frequency of the data. ${ }^{35}$ During the period of study, the duration variable is grouped and the grouping changes over time (see table A in the Appendix A for details). Before 1987, most of the durations groups include more than one quarter. After 1987, duration in the survey is reported in months if it is less than 2 years and in years if beyond that. This implies that if we estimate the same model specification for the entire sample period using 2 consecutive cross-sections every year, then only 2 duration categories can be distinguished. In the next section, we illustrate how we can modify the method to estimate finer duration categories by using more cross-sections, as discussed in section 3.1 .

\subsection{Second experiment}

We use data from years in which duration is not grouped and estimate the same model using two approaches: one uses two consecutive quarters of ungrouped duration, and the other uses multicross sections of artificially grouped duration data (the grouping is made in the same way as in the real data prior to 1987). The results are reported in Table 4. Overall, the two sets of estimates are very similar, which demonstrates that our estimation method works well even with the grouped duration data. This proves especially useful for our subsequent empirical analysis when the duration data were grouped in some years.

\footnotetext{
${ }^{35}$ Similarly, when estimating the model proposed in Nickell (1979), the frequency of the inflow is crucial in order to estimate the model semi-parametrically (see Güell (2001)).
} 


\section{Empirical Application}

In this section, we apply the proposed method to the full set of cross-sectional data over the period 1978-94 to analyze the changes in the duration distribution of unemployment between the 1980s and 1990s. We take the year 1984 as reference since the introduction of fixed-term or temporary contracts (TC) implies a big change in the dynamics in and out of unemployment and can potentially have a big impact on the duration distribution of unemployment. This reform was the most important reform during this time period. Unfortunately, a natural experiment approach cannot be taken in order to assess the effect of the introduction of TC on the duration distribution of unemployment. The reason is that all the workers were eligible for these new contracts and there was no group excluded and thus no control group. However, as explained above, TC played an important role in the changes in the flows of the labor market and therefore it is reasonable to expect that most of the changes we find in the duration distribution of unemployment should be related to it. We estimate the model distinguishing between the period before and after the 1984 labor market reform in Spain. ${ }^{36}$ Before we estimate the model, in the next two subsections, we discuss the results we expect to obtain from a theoretical point of view, and also provide a very brief review of the related empirical literature.

\subsection{Theoretical considerations}

As mentioned in the introduction, the observed changes in the share of long-term unemployed (LTU) only tell us that the average probability of leaving unemployment has increased. However, this fact does not tell us if the increased changes of leaving unemployment are equally shared among all the unemployed or, if instead, there are some unemployed workers that benefit more than others. This is a crucial question in order to fully understand the changes in the duration distribution of unemployment.

Consider that firms can either choose randomly among the pool of unemployed workers or, alternatively, firms can rank applicants by their spells of unemployment, hiring first those workers with shortest duration of unemployment (see Blanchard and Diamond, 1994). Consider then the introduction of TCs. This increases outflows from unemployment since these contracts are less costly than permanent contracts. To the extent that firms do not hire randomly, then are strong

\footnotetext{
${ }^{36}$ We use all available data (starting in 1976:3). Since duration is grouped until 1987, it implies that the first quarter that we can estimate our model is 1978:2 (see Table B in the Appendix A).
} 
arguments for the fact that duration dependence might have increased with the introduction of TCs. As Blanchard and Diamond (1994) show, if firms rank unemployed workers and hire those with the shortest spells of unemployment, then the exit rate from unemployment is a decreasing function of duration. In the extreme model where all unemployed workers were homogeneous and only duration of unemployment influenced workers' chances to leave unemployment, then the short-term unemployed (STU) would exit first after the introduction of TCs. And when their TC would finish, they would go back to unemployment and they would again be the unemployed with shortest spell and with higher chances of being re-employed than the others. Note that before the introduction of TC, the STU would also be the first ones to leave unemployment whenever there was a job offer. However, the fact that they were less likely to go back to unemployment because they were hired under a permanent contract implied that the LTU would move up in their ranking position, increasing their chances to leave unemployment. The same argument applies if there are some key demographics that make workers more employable than others, as long as workers maintain these key characteristics. So, after the introduction of TC, workers without such characteristics would tend to experience longer spells of unemployment than the others. The fact that workers that get jobs go back to unemployment implies that these characteristics would be even more unevenly distributed among unemployment spells (i.e. clustered among the shortest spells), implying again lower chances for the other unemployed workers to exit.

Consider now the increased female labor force participation. In this case, the new participants have the shortest duration of unemployment and therefore, ceteris paribus, higher chances to leave unemployment in the ranking model explained above. However, the overall effect depends on the employability characteristics of these new participants. If despite having short duration of unemployment their demographics are not favorable for leaving unemployed compared to the other unemployed workers, then they would tend to accumulate into longer spells of unemployment. Therefore the effects for females are ambiguous. ${ }^{37}$

\footnotetext{
${ }^{37}$ See also Abraham and Shimer (2002) for a discussion on the different effects of increased female labor force participation on unemployment duration.
} 


\subsection{Related Empirical Literature}

Most existing studies that analyze unemployment duration and the exit rates to employment in Spain concentrate on male unemployed. ${ }^{38}$ These papers find that there is a very strong duration dependence. Bover, Arellano and Bentolila (2002) and García-Pérez (1997) also find that fixed-term contracts increase the employment chances of the unemployed in Spain (for recent periods).

These studies typically use the Spanish Labor Force Survey in its panel format or other data sets which are also longitudinal. An exception is Güell (2001). She analyses the employment chances for male unemployed for the period 1980 to 1994 and uses single cross-section data of the Spanish Labor Force Survey by applying the method in Nickell (1979) and assuming the composition of inflow is constant over time. Her main finding is that duration dependence has increased in the early 1990s and explains how the introduction of fixed-term contracts may have caused this. Her results depend on the stationarity assumption.

The contribution of our paper to this empirical literature is therefore to analyze the evolution of the chances of leaving unemployment for both males and females over a long period of time. This is potentially important because females have a higher incidence of fixed-term contracts. ${ }^{39}$ Therefore, our analysis can help assess the overall effect of the reform. We estimate the probability of leaving unemployment using repeated cross-section data by applying the proposed econometric method, which does not impose any stationarity assumption.

There is also a growing literature that analyses different aspects of fixed-term contracts and the labor market performance. This literature has emphasized the segmentation among employed workers despite the ambiguous effects on aggregate employment. ${ }^{40}$ Our contribution to this literature is the analysis of the possible segmentation to the unemployed pool of workers.

\footnotetext{
${ }^{38}$ See, for instance, Alba (1999), Bover, Arellano and Bentolila (2002), García-Pérez (1997) and Jenkins and GarcíaSerrano (2000).

${ }^{39}$ For the period $1987-1994$, on average, $29 \%$ of employees were on a TC. For male workers, the fraction is $27 \%$ while for females is $34 \%$.

${ }^{40}$ See, for example, Alba (1994 and 1998), Aguirregabiria and Alonso-Borrego (1999), Alonso-Borrego, FernandezVillaverde and Galdón-Sánchez (2002), Bentolila and Dolado (1994), Bentolila and Saint-Paul (1992), Blanchard and Landier (2002), Booth, Francesconi and Frank (2002), Cabrales and Hopenhayn (1997), Cahuc and Postel-Vinay (2002), Jimeno and Toharia (1993 and 1996), Saint-Paul (1996) and Wasmer (1999).
} 


\subsection{Empirical results}

We first investigate the changes in the relative probability of leaving unemployment for the STU versus LTU for the pooled sample in order to get an idea of the possible changes for a typical worker. We then analyze these issues separately for different groups of unemployed workers (males, females, first job seekers and workers with previous job experience) in order to understand if there are important differences among these two duration groups. ${ }^{41}$

Table 5 reports the estimates for the pooled sample. We first concentrate on columns 1 and 2 which correspond to the estimates for all the years before the reform and for all the years after the reform, respectively. Given our goal is to investigate the changes in "duration dependence" over time, the main parameters of interest here are the coefficients on the set of the duration dummy variables. ${ }^{42}$ To aid the inspection, in Figure 2 we plot the estimated unemployment continuation probabilities functions of duration for a typical worker (see table 1a). ${ }^{43}$ Several patterns emerge from these results. First, as expected from the observed increase in outflow rates, the average probability of staying unemployed is lower in the post-reform period. Second, in both pre- and post-reform periods, the unemployment continuation probability monotonically increases over duration (except for the group with the shortest duration). ${ }^{44}$ This suggests, as previous studies have also encountered, that there has been negative "duration dependence" in unemployment. For our purpose, we will focus on the monotonic part of this function. Thirdly, after the reform, the STU have higher chances of exiting unemployment while the LTU stay the same. ${ }^{45}$ This results suggest that "duration dependence" has increased over this period of time. The effects of the different covariates are fairly standard. We highlight that females and first job seekers have lower chances of

\footnotetext{
${ }^{41}$ The model specification used here is the same as that of Table 4. Since the cross-sectional data provide additional information on family characteristics, we have, in both cases, added two more variables, namely, the number of kids and number of working adults in the household.

${ }^{42}$ Bover, Arellano and Bentolila (2002), using the panel version of Spanish Labor Force, control for unobserved heterogeneity but their results do not change qualitatively. In this sense, although we do not control for any form of unobserved heterogeneity, we are more confident about the "duration dependence" we find in our estimates.

${ }^{43}$ In this case, the typical worker is a man who has worked before with no children, 1 working adult in the household, has primary education or below, unmarried, age 20-24 years.

${ }^{44}$ A similar non-monotonic duration dependence has also been found in previous studies (see, for instance, Bover, Arellano and Bentolila, 2002).

${ }^{45}$ The t-statistics of the difference between the predicted probability before and after the reform are respectively: -2.511 (duration 1 quarter), -9.111 (duration 2-3 quarters), -0.174 (duration 4-7 quarters) and 0.536 (duration 8+ quarters).
} 
leaving unemployment. The coefficient on education suggests unemployed workers with secondary education and above have higher probabilities of staying unemployed, although this effect gets reduced in the post-reform period. ${ }^{46}$

While the sample period before the reform (1980-84) is a recession, the period after the reform includes some years of expansion (from 1985 to 1991) and some years of recession (from 1992 to 1994). As figure 1 shows, the LTU typically displays anti-clockwise loops over the cycle, that is, it lags behind the unemployment rate (see Machin and Manning, 1999). When unemployment starts to rise there is an increase in inflows into unemployment, implying at first an increase in the share of STU which then falls. Similarly, when unemployment starts falling the share of LTU increases first but then it falls. The consequence of this is that for given a level of unemployment, the incidence of LTU is generally higher in an expansion period than in a recession. This can imply that the "duration dependence" is higher in expansion years because the proportion of LTU is higher. In order to isolate the possible business cycle effect we re-estimate the model only for years 1983 and 1992, which are the most comparable in terms of unemployment rates (see figure 1). Columns (3) and (4) of table 5 report these estimates and in Figure 3 the estimated probability of staying unemployed is plotted. As can be seen, the duration pattern before and after the reform is comparable to the estimates with all the years. ${ }^{47}$ So we conclude that the increased "duration dependence" is not entirely due to a business cycle effect. ${ }^{48}$

As mentioned earlier, our model does not impose a proportional duration pattern among different population groups. Figure 4 illustrates this. The probability of staying unemployed at different durations is plotted for two different groups for the pre-reform (left hand graph) and post-reform

\footnotetext{
${ }^{46}$ Güell (2001) finds the same results for the years 1980-1984. Similarly, Bover, Arellano and Bentolila (2002) find that a university degree increases the hazard of leaving unemployment only during the first 3 months; afterwards the hazard reduces to levels below those of less educated workers. These findings are consistent with the higher incidence of LTU among higher educated unemployed individuals (Machin and Manning (1999), table 3).

${ }^{47}$ The only qualitative difference is with respect to the first duration dummy. When considering all the years, there is no difference. However when considering the single year estimates, the probability of staying unemployed is higher in 1992 than 1983. This has to do with the fact that, although these two years are comparable in terms of the unemployment rate, the first duration dummy is higher in 1992 than in 1983 . Moreover, 1992 is the first year for which the unemployment rate increases after a period of decreasing unemployment rates. When the unemployment rate starts increasing, the first effect is that the STU increase very much (see Machin and Manning, 1999).

${ }^{48}$ The t-statistics of the difference between the predicted probability before and after the reform are respectively: 3.608 (duration 1 quarter), -1.590 (duration 2-3 quarters), -1.091(duration 4-7 quarters) and 0.905 (duration 8+ quarters).
} 
period (right hand graph). As can be seen, in the pre-reform period, the probability of staying unemployed for group 2 is higher than for group 1 but the difference is not the same for every duration category. This is more evident in the post-reform period. Had we imposed a proportional duration model, then we would observe the same distance for every duration category between the two groups in the two graphs. These results show that the changes in the chances of leaving unemployment after the reform for the different duration categories can be very different for different population groups. This is very important from a policy point of view. In this particular example, the probability of leaving unemployment of group 2 is even lower in the post-reform period. This can be explained by the change in the magnitude of some coefficients before and after the reform (see table 5).

We now turn to the analysis for different population groups, by gender and previous work experience. We first analyzed the differences between the typical men and typical women in the sample both with and without previous job experience. We found very similar pattern across genders for these two groups. We then analyzed the differences between unemployed workers with previous experience and first job seekers. A substantial part of the increase in labor force participation can be analyzed through first job seekers. ${ }^{49}$ Table 6 reports the estimates for these two groups before and after the reform. In Figure 5, the estimated unemployment continuation probability function is plotted for a typical worker who has worked before as well as the typical first job seeker (see tables $1 \mathrm{~b}$ and 1c).

For workers with previous experience, we find very similar duration patterns as in the pooled sample. ${ }^{50}$ This is in part due to the large fraction of males who have worked before in the pooled sample. That is, "duration dependence" has increased over this period of time partly due to the increased chances of leaving unemployment of the STU. However, for first job seekers the picture is more different. First, the probability of staying unemployed is very high for any duration category. Secondly, in the pre-reform period there was no clear "duration dependence" pattern, while after the reform we do find negative "duration dependence". However, in this case it is due to the fact

\footnotetext{
${ }^{49}$ Estimates of yearly transitions using the panel version of the Spanish LFS show that for the period 1984-94, on average, among workers who were first job seekers, $60 \%$ were first job seekers one year ago and $32 \%$ were out of the labor force.

${ }^{50}$ The t-statistics of the difference between the predicted probability before and after the reform are respectively: -0.874 (duration 1 quarter), -4.956 (duration 2-3 quarters), 0.563 (duration 4-7 quarters) and 1.365 (duration 8+ quarters).
} 
that the LTU experienced a much higher chance of staying unemployed than previously. ${ }^{51}$ First job seekers are mostly unmarried females with secondary education or more. As table 6 shows, these characteristics affect adversely the chances of leaving unemployment.

Overall, we conclude that the changes between the mid-80s and mid-90s for a typical male worker (e.g. with previous work experience) were concentrated among the STU who experienced higher chances of leaving unemployment. For females, since the composition of workers with and without experience is about half each, the effects of first job seekers are more important. That is, there are also some changes concentrated among the LTU who experienced lower chances of leaving unemployment.

\section{Conclusion}

The goal of this paper is to analyze the changes in the probability of leaving unemployment in Spain for different groups of unemployed workers during the 1980s and 1990s when fixed-term contracts were introduced. Panel data is not available for all this period of time so we have to rely on cross-sectional data from the Labor Force Survey. This leads us to construct a new method based on the method of moments that uses repeated cross-section data on unemployed individuals. The most important features of the method are that it estimates the exit probability at the individual level and thus avoids the small cell problem encountered in previous studies; and that it relaxes any stationarity assumption on the composition of inflows into unemployment (Nickell, 1979). Furthermore, the estimation method can be easily modified to take into account grouped duration data and time-varying covariates. Experiments comparing, on the one hand, the GMM estimates using two cross-sections to the logit estimates using the panel and, on the other hand, the GMM estimates using two and multiple cross-sections (with grouped durations) indicate that our method performs reasonably well. This suggests that in the absence of panel data, our method can be used to analyze the probability of leaving unemployment by combining cross-sections.

The proposed method can have other applications beyond the one analyzed here. The method is applicable for any duration analysis whenever cross section instead of panel data are available, or more suitable (e.g. welfare dependence, employment tenure, etc.).

We have analyzed the changes in the duration distribution for both men and females with and

\footnotetext{
${ }^{51}$ The t-statistics of the difference between the predicted probability before and after the reform are respectively: 1.618 (duration 1 quarter), -2.295 (duration 2-3 quarters), 4.211 (duration 4-7 quarters) and -0.188 (duration 8+ quarters).
} 
without previous work experience. To our knowledge, this is the first study that undertakes this analysis for females using the Spanish Labor Force Survey (owing to the richer information of family background in the cross section data!). Our results suggest that the unemployed pool becomes more segmented in the 1990s. Specifically, the relative probability of leaving unemployment of the shortterm unemployed versus the long-term unemployed becomes significantly higher in 1990s. In this sense, our results would indicate that more targeted policies towards the long-term unemployed can be beneficial in reducing unemployment.

We have pointed out the most obvious candidates for the changes in the flows of the labor market, that is, the introduction of temporary contracts in 1984 as well as the increase in female labor force participation. Obviously, it is possible that during the period of time analyzed there were also some underlying structural changes in the Spanish economy. As discussed, the important thing is that, at least in the labor market, the changes have mostly materialized through temporary contracts. 


\section{References}

[1] Abbring, J.H., G. J. van den Berg, and J.C. van Ours (2002), "The anatomy of unemployment dynamics", European Economic Review, 46, 1785-1824.

[2] Abraham, K. and R. Shimer (2002), "Changes in Unemployment Duration and Labor Force Attachment," in The Roaring Nineties, edited by A. Krueger and R. Solow. Russell Sage Foundation.

[3] Aguirregabiria, V. and C. Alonso-Borrego (1999), "Labor contracts and flexibility: evidence from a labor market reform in Spain", Universidad Carlos III Working Paper No 99-27

[4] Alba, A. (1994), "Formal training, temporary contracts, productivity and wages in Spain", Oxford Bulletin of Economics and Statistics, 56 (2), 151-170.

[5] Alba, A. (1998), "How temporary is temporary employment in Spain?", Journal of Labor Research, 19 (4), 695-710.

[6] Alba, A. (1999), "Explaining the transitions out of unemployment in Spain: the effect of unemployment insurance", Applied Economics, 31, 183-193.

[7] Alonso-Borrego, C., J. Fernandez-Villaverde and J.E. Galdón-Sánchez (2002), "Evaluating Labor Market Reforms: A General Equilibrium Approach", mimeo, University of Pennsylvania.

[8] Angrist, J. and A. Krueger (1992), "The Effect of Age at School Entry on Educational Attainment: An Application of Instrumental Variables with Moments from Two Samples," Journal of the American Statistical Association, 87, 328-36.

[9] Arellano, M. and C. Meghir (1992), "Female Labour Supply and On-the-Job Search: An Empirical Model Estimated Using Complementary Data Sets," Review of Economic Studies, $59,537-59$.

[10] Baker, M. (1992), "Unemployment Duration: Compositional Effects and Cyclical Variability," American Economic Review, 82, 313-321.

[11] Bentolila, S. and J. J. Dolado (1994), "Labour flexibility and wages: lessons from Spain", Economic Policy, 18, 53-99.

[12] Bentolila, S. and G. Saint-Paul (1992), "The macroeconomic impact of flexible labor contracts, with an application to Spain", European Economic Review, 36, 1013-1053.

[13] Blanchard, O. and P. Diamond (1994), "Ranking, Unemployment Duration, and Wages," Review of Economic Studies, 61, 417-434.

[14] Blanchard, O. and A. Landier (2002): "The Perverse Effects of Partial Labor Market Reforms: Fixed Duration Contracts in France", forthcoming Economic Journal, Features: Symposium on Temporary Work. 
[15] Blundell, R., C. Meghir and P. Neves (1993) "Labour supply and intertemporal substitution", Journal of Econometrics, 59, 137-160

[16] Booth, A. L., M. Francesconi and J. Frank (2002), "Temporary Jobs: Stepping Stones or Dead Ends?", forthcoming Economic Journal, Features: Symposium on Temporary Work.

[17] Bover, O., M. Arellano and S. Bentolila (2002), "Unemployment duration, benefit duration, and the business cycle", The Economic Journal, 112 (479), 223-265.

[18] Browning, M., A. Deaton, M. Irish (1985), "A Profitable Approach to Labor Supply and Commodity Demands over the Life-Cycle", Econometrica, 53 (3), 503-544.

[19] Cabrales, A. and H. A. Hopenhayn (1997), "Labor-market flexibility and aggregate employment volatility", Carnegie-Rochester Conference Series on Public Policy 46, 189-228.

[20] Cahuc, P. and F. Postel-Vinay (2002), "Temporary jobs, employment protection and labor market performance", Labour Economics (9) 1, 63-91, .

[21] Cockx, B. (1997), "Analysis of transition Data by the Minimum-Chi-Square Method: An Application to Welfare Spells in Belgium," Review of Economics and Statistics, 79, 392-405.

[22] Deaton, A. (1985): "Panel data from time series of cross-sections", Journal of Econometrics, 30, 109-126.

[23] Galdón-Sánchez, J.E. and M. Güell (2000): "Let's go to court! Firing costs and Dismissal conflicts", Industrial Relations Section, Princeton University, Working Paper No. 444

[24] García-Pérez, J. I. (1997), "Las tasas de salida del empleo y el desempleo en España (19781993)", Investigaciones Económicas, vol XXI (1), 29-53.

[25] Grubb, D. and W. Wells (1993), "Employment Regulation and patterns of work in EC countries", OECD Economic Studies, 21, 7-58.

[26] Güell, M. (2001), "Fixed-term Contracts and the Duration Distribution of Unemployment", Centre for Economic Performance, London School of Economics, Discussion Paper n. 505.

[27] Hansen, L. (1982): "Large Sample Properties of Generalized Method of Moments Estimators," Econometrica, 50, 1029-1054.

[28] Heckman, J. J. and R. Robb, Jr. (1985), "Alternative methods for evaluating the impact of interventions", Longitudinal analysis of labor market data, Econometric Society Monographs No. 10, edited by J.J. Heckman and B. Singer, Cambridge University Press.

[29] Imbens, G. and T. Lancaster (1994), "Combining Micro and Macro Data in Microeconometric Models," Review of Economic Studies, 61, 655-80.

[30] Jenkins, S. P. and C. García-Serrano (2000), "Re-employment probabilities for Spanish men and the role of unemployment benefits" Institute for Social and Economic Research, University of Essex,Working Paper 2000-17. 
[31] Jimeno, J. F. and L. Toharia (1993), "The effects of fixed-term employment on wages: theory and evidence from Spain", Investigaciones Economicas, XVII (3), 475-494.

[32] Jimeno, J. F. and L. Toharia (1996), "Effort, absenteeism, and fixed term employment contracts", Revista Española de Economia, 13 (1), 105-119.

[33] Lancaster, T. (1990), The Econometric Analysis of Transition Data, Cambridge: Cambridge University Press.

[34] Manski, C.F. and S. R. Lerman (1977), "The Estimation of Choice Probabilities from Choice Based Samples", Econometrica, 45 (8), 1977-1988.

[35] Manski, C.F. and D. L. McFadden (1981), "Alternative Estimators and Sample Designs for Discrete Choice Analysis" in Structural Analysis of Discrete Data and Econometric Applications, Cambridge: The MIT Press.

[36] Machin, S. and A. Manning (1999), "The causes and consequences of long-term unemployment in Europe" in Orley Ashenfelter and David Card (eds.), Handbook of Labor Economics, Volume 3. Amsterdam: North-Holland.

[37] Moffit, R. (1993), "Identification and estimation of dynamic models with a time series of repeated cross-sections", Journal of Econometrics, 59, 99-123.

[38] Newey, W. and D. McFadden (1994): "Large Sample Estimation and Hypothesis Testing," in R. Engle and D. McFadden eds. Handbook of Econometrics, Volume 4, Elsevier, North-Holland, 2111-2245.

[39] Nickell, S. J. (1979), "Estimating the probability of leaving unemployment", Econometrica, 47 (5), 1249-1266.

[40] OECD (1999), Employment Outlook, Paris.

[41] Saint-Paul, G. (1996), "Dual labor markets, a macroeconomic perspective", Cambridge, MA: MIT Press.

[42] Sider, H. (1985), "Unemployment Duration and Incidence: 1968-82," American Economic Review, 75, 461-472.

[43] Van den Berg, G. J. (2001), "Duration Models: Specification, Identification, and Multiple Durations," in J. Heckman and E. Leamer eds. Handbook of Economertics, volume V. NorthHolland, Amsterdam.

[44] Van den Berg, G. J. and B. van der Klaauw (2001), "Combining Micro and Macro Unemployment Duration data," Journal of Econometrics, 102, 271-309.

[45] Van den Berg, G. J., and J. C. van Ours (1994), "Unemployment Dynamics and Duration Dependence in France, the Netherlands and the United Kingdom," Economic Journal, 104, $432-43$. 
[46] Van den Berg, G. J., and J. C. van Ours (1996), "Unemployment Dynamics and Duration Dependence," Journal of Labor Economics, 14, 100-125.

[47] Wasmer, E. (1999), "Competition for jobs in a growing economy and the emergence of dualism in employment", Economic Journal, 109, 349-371. 
Table 1a: Summary Statistics (Pooled sample)*

\begin{tabular}{lcccc}
\hline \hline & $(1)$ & $(2)$ & $(3)$ & $(4)$ \\
& $1978-84(\mathrm{I})$ & $1978-84(\mathrm{II})$ & $1985-94(\mathrm{I})$ & $1985-94(\mathrm{II})$ \\
\hline Age 20-24 & 0.376 & 0.382 & 0.311 & 0.328 \\
& $(0.484)$ & $(0.486)$ & $(0.463)$ & $(0.469)$ \\
Age 25-34 & 0.283 & 0.273 & 0.348 & 0.340 \\
Age 35-49 & $(0.450)$ & $(0.445)$ & $(0.476)$ & $(0.473)$ \\
& 0.200 & 0.203 & 0.219 & 0.208 \\
Age 50+ & $(0.400)$ & $(0.402)$ & $(0.414)$ & $(0.405)$ \\
& 0.141 & 0.142 & 0.121 & 0.124 \\
Married & $(0.348)$ & $(0.349)$ & $(0.326)$ & $(0.329)$ \\
& 0.450 & 0.450 & 0.457 & 0.449 \\
Secondary edu. \&above & $(0.497)$ & $(0.497)$ & $(0.498)$ & $(0.497)$ \\
N.of kids & 0.367 & 0.352 & 0.536 & 0.519 \\
& $(0.481)$ & $(0.477)$ & $(0.499)$ & $(0.499)$ \\
N. of working adults & 1.012 & 1.037 & 0.826 & 0.846 \\
& $(1.319)$ & $(1.357)$ & $(1.074)$ & $(1.106)$ \\
First job seeker & 0.843 & 0.873 & 0.858 & 0.859 \\
& $(0.894)$ & $(0.912)$ & $(0.865)$ & $(0.871)$ \\
Female & 0.290 & 0.291 & 0.242 & 0.262 \\
& $(0.453)$ & $(0.454)$ & $(0.428)$ & $(0.439)$ \\
\hline No. obs & 0.300 & 0.299 & 0.458 & 0.442 \\
\hline \hline Note: & $(0.458)$ & $(0.458)$ & $(0.498)$ & $(0.496)$ \\
\hline
\end{tabular}

Note: $\left({ }^{*}\right)(\mathrm{I})$ refers to second quarters of each year and (II) refers to the previous quarters;

(1) Standard deviations in parenthesis; (2) Source: EPA; 
Table 1b: Summary Statistics (Worked before sample)*

\begin{tabular}{lcccc}
\hline \hline & $(1)$ & $(2)$ & $(3)$ & $(4)$ \\
& $1978-84(\mathrm{I})$ & $1978-84(\mathrm{II})$ & $1985-94(\mathrm{I})$ & $1985-94(\mathrm{II})$ \\
\hline Age 20-24 & 0.259 & 0.265 & 0.224 & 0.231 \\
Age 25-34 & $(0.438)$ & $(0.441)$ & $(0.417)$ & $(0.421)$ \\
& 0.299 & 0.288 & 0.354 & 0.350 \\
Age 35-49 & $(0.458)$ & $(0.453)$ & $(0.478)$ & $(0.477)$ \\
& 0.255 & 0.259 & 0.266 & 0.257 \\
Age 50+ & $(0.436)$ & $(0.438)$ & $(0.442)$ & $(0.437)$ \\
& 0.187 & 0.188 & 0.155 & 0.162 \\
Married & $(0.390)$ & $(0.391)$ & $(0.362)$ & $(0.369)$ \\
& 0.564 & 0.563 & 0.543 & 0.545 \\
Secondary edu. \&above & $(0.496)$ & $(0.496)$ & $(0.498)$ & $(0.498)$ \\
& 0.225 & 0.205 & 0.450 & 0.421 \\
N.of kids & $(0.417)$ & $(0.404)$ & $(0.497)$ & $(0.494)$ \\
& 1.148 & 1.177 & 0.905 & 0.937 \\
N. of working adults & $(1.382)$ & $(1.425)$ & $(1.111)$ & $(1.149)$ \\
& 0.731 & 0.761 & 0.791 & 0.781 \\
Female & $(0.874)$ & $(0.896)$ & $(0.853)$ & $(0.859)$ \\
& 0.210 & 0.207 & 0.401 & 0.379 \\
No. obs & $(0.407)$ & $(0.405)$ & $(0.490)$ & $(0.485)$ \\
\hline \hline
\end{tabular}

Note: $\left(^{*}\right)(\mathrm{I})$ refers to second quarters of each year and (II) refers to the previous quarters;

(1) Standard deviations in parenthesis; (2) Source: EPA. 
Table 1c: Summary Statistics (First Job Seekers)*

\begin{tabular}{lcccc}
\hline \hline & $(1)$ & $(2)$ & $(3)$ & $(4)$ \\
& $1978-84(\mathrm{I})$ & $1978-84(\mathrm{II})$ & $1985-94(\mathrm{I})$ & $1985-94(\mathrm{II})$ \\
\hline Age 20-24 & 0.662 & 0.668 & 0.583 & 0.602 \\
Age 25+ & $(0.473)$ & $(0.471)$ & $(0.493)$ & $(0.489)$ \\
& 0.337 & 0.332 & 0.417 & 0.397 \\
Married & $(0.473)$ & $(0.471)$ & -0.493 & $(0.489)$ \\
& 0.169 & 0.173 & 0.186 & 0.178 \\
Secondary & $(0.375)$ & $(0.378)$ & $(0.389)$ & $(0.383)$ \\
& 0.715 & 0.708 & 0.805 & 0.797 \\
N.of kids & $(0.452)$ & $(0.455)$ & $(0.396)$ & $(0.402)$ \\
& 0.68 & 0.697 & 0.578 & 0.589 \\
N. of working adults & $(1.082)$ & $(1.103)$ & $(0.907)$ & $(0.929)$ \\
& 1.118 & 1.148 & 1.071 & 1.078 \\
Female & $(0.884)$ & $(0.893)$ & $(0.868)$ & $(0.870)$ \\
& 0.52 & 0.524 & 0.639 & 0.621 \\
No. obs & $(0.500)$ & $(0.499)$ & $(0.480)$ & $(0.485)$ \\
\hline \hline
\end{tabular}

Note: $\left({ }^{*}\right)(\mathrm{I})$ refers to second quarters of each year and (II) refers to the previous quarters;

(1) Standard deviations in parenthesis; (2) Source: EPA 
Table 2: Summary Statistics for the experiment data

\begin{tabular}{|c|c|c|c|}
\hline & \multicolumn{2}{|c|}{ cross-section } & \multirow[t]{2}{*}{ panel } \\
\hline & 1988:1 & 1988:2 & \\
\hline Age25-34 & $\begin{array}{c}0.300 \\
(0.458)\end{array}$ & $\begin{array}{c}0.303 \\
(0.460)\end{array}$ & $\begin{array}{c}0.300 \\
(0.458)\end{array}$ \\
\hline Age35-49 & $\begin{array}{c}0.256 \\
(0.437)\end{array}$ & $\begin{array}{c}0.259 \\
(0.438)\end{array}$ & $\begin{array}{c}0.256 \\
(0.437)\end{array}$ \\
\hline Age $50+$ & $\begin{array}{c}0.220 \\
(0.414)\end{array}$ & $\begin{array}{c}0.225 \\
(0.417)\end{array}$ & $\begin{array}{c}0.220 \\
(0.414)\end{array}$ \\
\hline Married & $\begin{array}{c}0.546 \\
(0.498)\end{array}$ & $\begin{array}{c}0.547 \\
(0.498)\end{array}$ & $\begin{array}{c}0.546 \\
(0.498)\end{array}$ \\
\hline Secondary edu. \& above & $\begin{array}{c}0.357 \\
(0.479)\end{array}$ & $\begin{array}{c}0.357 \\
(0.479)\end{array}$ & $\begin{array}{c}0.357 \\
(0.479)\end{array}$ \\
\hline Survival in unemployment & & & $\begin{array}{c}0.669 \\
(0.471) \\
\end{array}$ \\
\hline No. of obs. & 3,639 & 3,639 & 3,639 \\
\hline
\end{tabular}

Note: (1) Standard deviations in parenthesis; (2) Source: EPA.

Table 3: Panel and Cross-section Estimates (1988 Male Sample)

\begin{tabular}{lccccc}
\hline \hline \multirow{2}{*}{ Explanatory Variables } & \multicolumn{2}{c}{ Panel Logit } & & \multicolumn{2}{c}{ Cross-section GMM } \\
& Coeff & S.E. & & Coeff & S.E. \\
\cline { 2 - 3 } \cline { 5 - 6 } Duration quarter 1 & -0.056 & 0.113 & & -0.074 & 0.220 \\
Duration quarter 2 & 0.140 & 0.119 & & 0.116 & 0.233 \\
Duration quarters 3-4 & 0.504 & 0.130 & & 0.493 & 0.272 \\
Duration quarters 5-7 & 0.913 & 0.137 & & 0.919 & 0.322 \\
Duration quarters 8+ & 0.944 & 0.114 & & 0.937 & 0.247 \\
Age 25-34 & 0.190 & 0.105 & & 0.148 & 0.225 \\
Age 35-49 & 0.340 & 0.126 & & 0.293 & 0.274 \\
Age 50+ & 0.567 & 0.137 & & 0.554 & 0.310 \\
Married & -0.219 & 0.091 & & -0.210 & 0.203 \\
Secondary edu. \& above & 0.140 & 0.087 & 0.223 & 0.192 \\
\cline { 5 - 6 } No. of obs. & 3,639 & & \\
\hline \hline
\end{tabular}

Source: EPA. 
Table 4: GMM Estimates Using Two vs. Multi-cross section (1988-94 Male Sample)

\begin{tabular}{|c|c|c|c|c|}
\hline \multirow[t]{2}{*}{ Explanatory Variables } & \multicolumn{2}{|c|}{$\begin{array}{l}2 \text { cross sections } \\
\text { ungrouped duration }\end{array}$} & \multicolumn{2}{|c|}{$\begin{array}{l}\text { multi-cross sections } \\
\text { grouped duration }\end{array}$} \\
\hline & Coeff & S.E. & Coeff & S.E. \\
\hline Duration quarter 1 & 0.862 & 0.154 & 0.838 & 0.104 \\
\hline Duration quarter 2-3 & 0.457 & 0.141 & 0.474 & 0.067 \\
\hline Duration quarters 4-7 & 0.984 & 0.163 & 0.991 & 0.089 \\
\hline Duration quarters $8+$ & 2.114 & 0.268 & 1.804 & 0.196 \\
\hline No. of kids & -0.056 & 0.049 & -0.078 & 0.019 \\
\hline No. working adults & -0.024 & 0.056 & 0.012 & 0.021 \\
\hline Secondary edu. \& above & 0.395 & 0.116 & 0.272 & 0.044 \\
\hline Married & -0.064 & 0.140 & -0.096 & 0.051 \\
\hline Age $25-34$ & 0.174 & 0.136 & 0.412 & 0.050 \\
\hline Age $35-49$ & 0.443 & 0.172 & 0.654 & 0.063 \\
\hline Age $50+$ & 0.764 & 0.225 & 0.718 & 0.074 \\
\hline No. of obs. & \multicolumn{2}{|c|}{18,711} & \multicolumn{2}{|c|}{18,711} \\
\hline
\end{tabular}

Source: EPA. 
Table 5: Estimation Results from Cross Section Data 1978-94

\begin{tabular}{|c|c|c|c|c|}
\hline & (1) & $\overline{~(2) ~}$ & 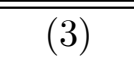 & (4) \\
\hline & $1978-84$ & 1985-94 & 1983 & 1992 \\
\hline \multirow[t]{2}{*}{ Duration quarter 1} & 1.038 & 0.784 & 0.894 & 2.237 \\
\hline & $(0.069)$ & $(0.052)$ & $(0.193)$ & $(0.496)$ \\
\hline \multirow[t]{2}{*}{ Duration quarter 2-3 } & 0.82 & 0.301 & 0.733 & 0.262 \\
\hline & $(0.047)$ & $(0.033)$ & $(0.124)$ & $(0.104)$ \\
\hline \multirow[t]{2}{*}{ Duration quarter 4-7 } & 1.057 & 1.001 & 1.168 & 0.773 \\
\hline & $(0.056)$ & $(0.046)$ & $(0.156)$ & $(0.139)$ \\
\hline \multirow[t]{2}{*}{ Duration quarter $8+$} & 2.003 & 2.059 & 1.684 & 1.633 \\
\hline & $(0.163)$ & $(0.085)$ & $(0.295)$ & $(0.261)$ \\
\hline \multirow[t]{2}{*}{ N.of kids } & -0.043 & -0.042 & -0.031 & -0.042 \\
\hline & $(0.01)$ & $(0.009)$ & $(0.027)$ & $(0.029)$ \\
\hline \multirow[t]{2}{*}{ N. of working adults } & -0.011 & 0.032 & 0.003 & 0.021 \\
\hline & $(0.015)$ & $(0.011)$ & $(0.042)$ & $(0.031)$ \\
\hline \multirow[t]{2}{*}{ Secondary edu.\& above } & 0.417 & 0.314 & 0.391 & 0.196 \\
\hline & $(0.038)$ & $(0.022)$ & $(0.094)$ & $(0.07)$ \\
\hline \multirow[t]{2}{*}{ Married } & -0.138 & -0.01 & -0.252 & 0.012 \\
\hline & $(0.036)$ & $(0.024)$ & $(0.094)$ & $(0.075)$ \\
\hline \multirow[t]{2}{*}{ Age $25-34$} & 0.404 & 0.412 & 0.546 & 0.465 \\
\hline & $(0.041)$ & $(0.026)$ & $(0.109)$ & $(0.078)$ \\
\hline \multirow[t]{2}{*}{ Age $35-49$} & 0.311 & 0.595 & 0.495 & 0.655 \\
\hline & $(0.044)$ & $(0.032)$ & $(0.114)$ & $(0.1)$ \\
\hline \multirow[t]{2}{*}{ Age $50+$} & 0.492 & 0.58 & 0.833 & 0.658 \\
\hline & $(0.051)$ & $(0.037)$ & $(0.138)$ & $(0.128)$ \\
\hline \multirow[t]{2}{*}{ First job seeker } & 0.377 & 0.835 & 0.786 & 0.928 \\
\hline & $(0.04$ & $(0.037$ & $(0.119$ & $(0.136$ \\
\hline \multirow[t]{2}{*}{ Female } & 0.35 & 0.44 & 0.287 & 0.421 \\
\hline & $(0.035)$ & $(0.02)$ & $(0.091)$ & $(0.059)$ \\
\hline No. obs & 45,628 & 120,765 & 8,467 & 11,797 \\
\hline
\end{tabular}

Notes: (1) Standard errors in parenthesis; (2) Source: EPA. 
Table 6. Estimation Results from Cross Section Data 1978-94

\begin{tabular}{lcccc}
\hline \hline & \multicolumn{2}{c}{ First job seekers } & \multicolumn{2}{c}{ Worked before } \\
& $(1)$ & $(2)$ & $(3)$ & $(4)$ \\
& $1978-84$ & $1985-94$ & $1978-84$ & $1985-94$ \\
\hline Duration quarter 1 & 1.382 & 1.77 & 1.006 & 0.778 \\
& $(0.217)$ & $(0.406)$ & $(0.075)$ & $(0.055)$ \\
Duration quarter 2-3 & 1.568 & 0.867 & 0.749 & 0.33 \\
& $(0.149)$ & $(0.132)$ & $(0.05)$ & $(0.034)$ \\
Duration quarter 4-7 & 1.142 & 1.66 & 1.125 & 1.023 \\
& $(0.134)$ & $(0.19)$ & $(0.063)$ & $(0.048)$ \\
Duration quarter 8+ & 2.615 & 2.241 & 1.971 & 2.172 \\
& $(0.461)$ & $(0.226)$ & $(0.192)$ & $(0.132)$ \\
N.of kids & -0.1 & -0.025 & -0.032 & -0.042 \\
N. of working adults & $(0.03)$ & $(0.04)$ & $(0.01)$ & $(0.009)$ \\
Secondary edu. \& above & -0.075 & 0.012 & 0.015 & 0.041 \\
& $(0.04)$ & $(0.041)$ & $(0.016)$ & $(0.01)$ \\
Married & 0.36 & 0.382 & 0.43 & 0.311 \\
& $(0.086)$ & $(0.093)$ & $(0.042)$ & $(0.022)$ \\
Age 25+, Age 25-34* & -0.536 & -0.551 & -0.115 & 0.015 \\
& $(0.116)$ & $(0.14)$ & $(0.037)$ & $(0.024)$ \\
Age 35-49 & 0.468 & 0.711 & 0.362 & 0.362 \\
Age 50+ & $(0.107)$ & $(0.117)$ & $(0.041)$ & $(0.024)$ \\
Nomale obs & & & 0.301 & 0.578 \\
& & & $(0.044)$ & $(0.031)$ \\
& & & 0.537 & 0.567 \\
& 0.746 & 0.919 & 0.195 & 0.377 \\
& $(0.077)$ & $(0.08)$ & $(0.039)$ & $(0.02)$ \\
& 13,219 & 29,206 & 32,409 & 91,559 \\
\hline \hline
\end{tabular}

Notes: $\left({ }^{*}\right)$ Age 25+ for first job seekers; Age 25-34 for worked before;

(1) Standard errors in parenthesis; (2) Source: EPA. 
Figure 1: The incidence of LTU and the unemployment rate, 1978-1996. Source: EPA.

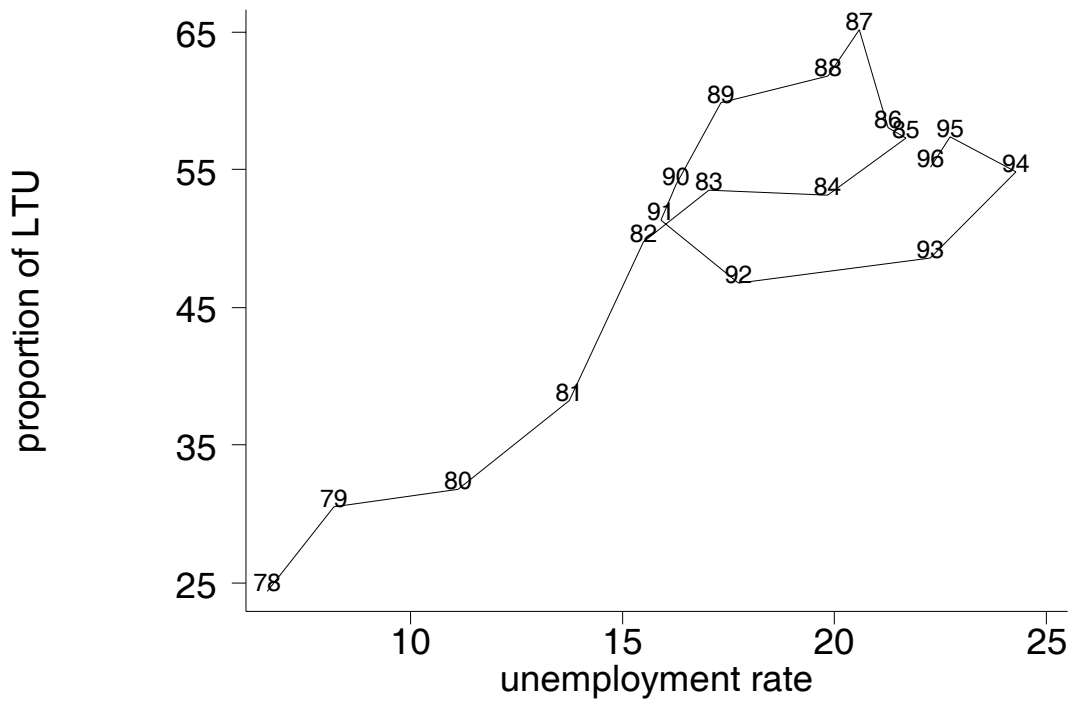

Figure 2: Estimated Unemployment Continuation Probability by Duration.

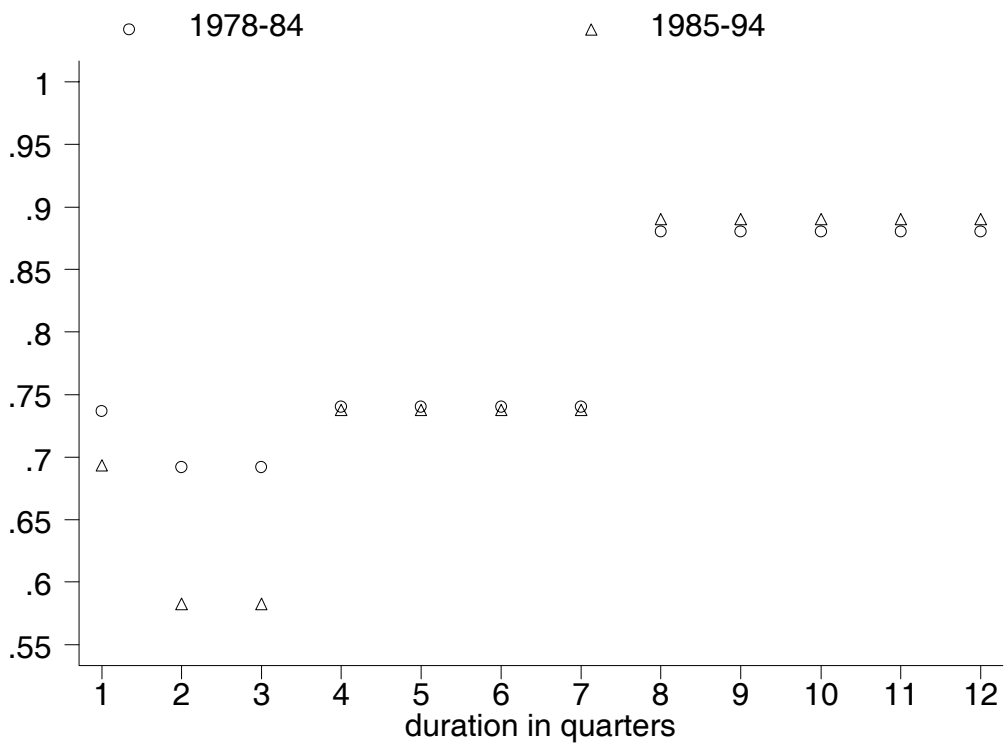

Ref. category: male, worked before, no child, 1 working adult, primary edu. or below, not married, age 20-24 (table 5, col. 1-2). 
Figure 3: Estimated Unemployment Continuation Probability by Duration.

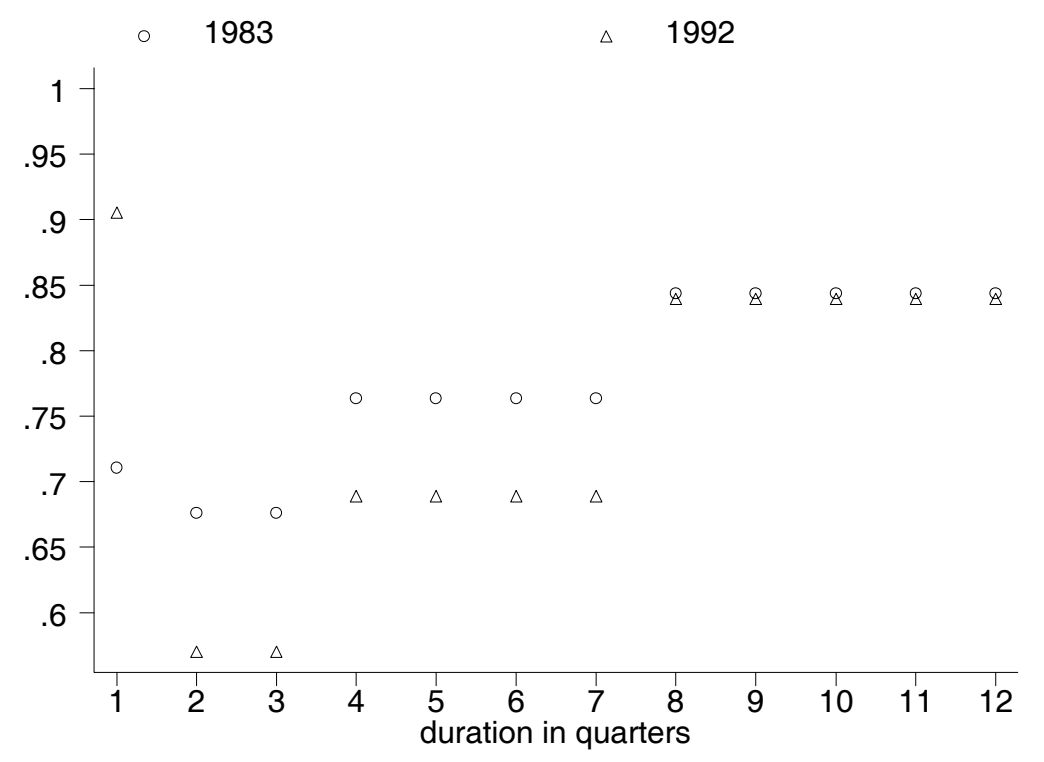

Ref. category: male, worked before, no child, 1 working adult, primary edu. or below, not married, age 20-24 (table 5, col. 3-4).

Figure 4: Estimated Unemployment Continuation Probability by Duration.
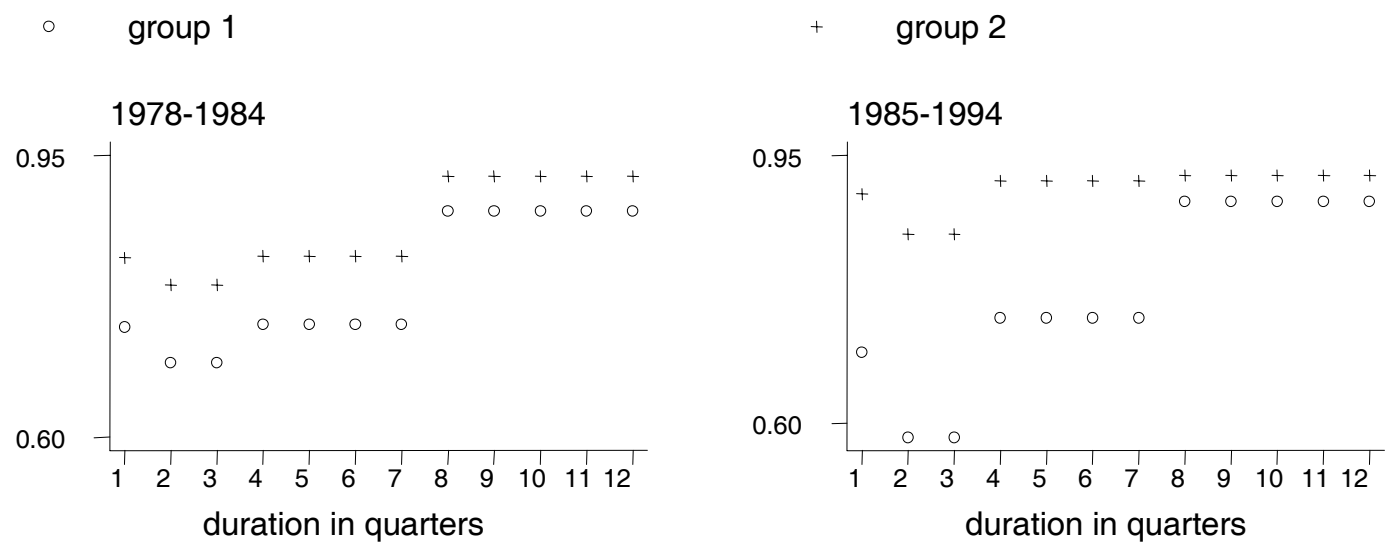

Group 1: male, worked before, no child, 1 working adult, primary edu. or below, not married, age 20-24. Group 2: male, first job seeker, 1 child, 1 working adult, primary edu. or below, married, age 35-49 (table 5, col. 1-2). 
Figure 5: Estimated Unemployment Continuation Probability by Duration.
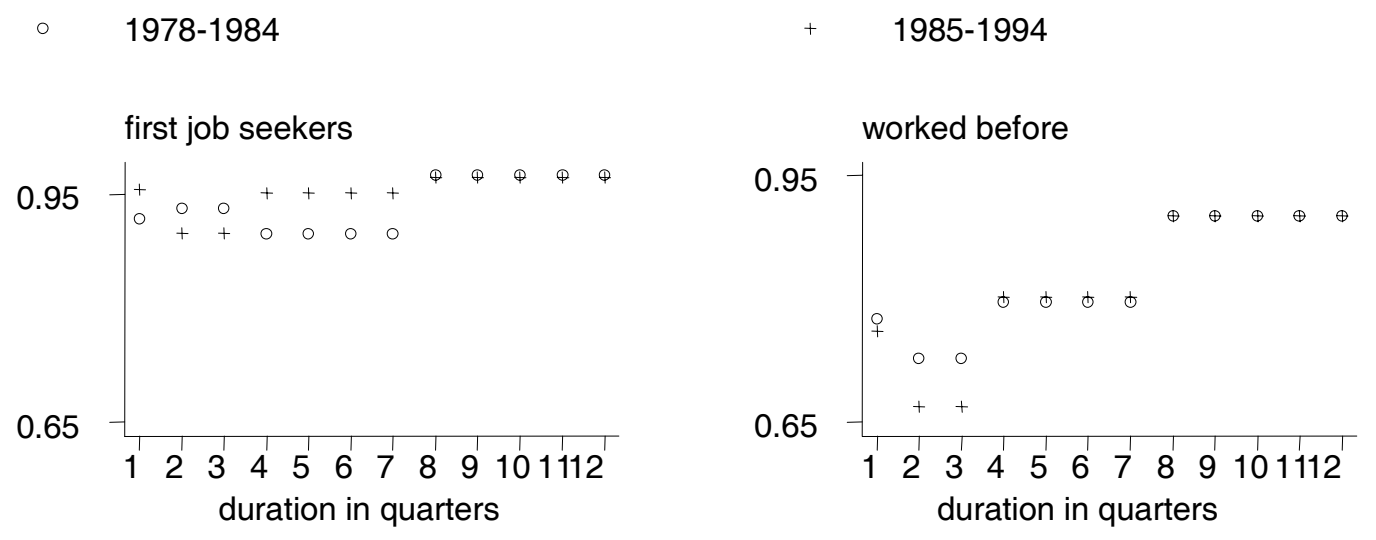

First job seekers: female, no child, 1 working adult, secondary edu. and above, not married, age 20-24. Worked before: male, 1 child, 1 working adult, primary edu. or below, married, age 25-34 (table 6). 


\section{Appendix A}

Table A. The duration of the unemployment in the EPA

\begin{tabular}{ccc}
\hline \hline until $1987(\mathrm{I})$ & 1987 (II) - 1991(VI) & from 1992 (I) \\
\hline How long have you & How long have you & Which day did you \\
been looking for a job? & been looking for a job? & start looking for a job? \\
Less than 1 month & If less than 2 years, & Month \\
1 to 3 months & number of months & \\
3 to 6 months & & \\
6 months to 1 year & If 2 years or more, & Year \\
1 to 2 years & number of years & \\
2 years or more & & \\
\hline \hline
\end{tabular}

Table B: Illustration of Matching Grouped Duration from Multi-Cross Sections

\begin{tabular}{ccccccccc}
\hline $\mathrm{t}-8$ & $\mathrm{t}-7$ & $\mathrm{t}-6$ & $\mathrm{t}-5$ & $\mathrm{t}-4$ & $\mathrm{t}-3$ & $\mathrm{t}-2$ & $\mathrm{t}-1$ & $\mathrm{t}$ \\
\hline 1 & 1 & 1 & 1 & 1 & 1 & 1 & $\mathbf{1}$ & 1 \\
\hdashline 2 & 2 & 2 & 2 & 2 & 2 & 2 & 2 & 2 \\
\hdashline 3 & 3 & 3 & 3 & 3 & 3 & 3 & 3 & 3 \\
4 & 4 & 4 & 4 & 4 & 4 & 4 & 4 & 4 \\
\hline 5 & 5 & 5 & 5 & 5 & 5 & 5 & 5 & 5 \\
6 & 6 & 6 & 6 & 6 & 6 & 6 & 6 & 6 \\
7 & 7 & 7 & 7 & 7 & 7 & 7 & 7 & 7 \\
8 & 8 & 8 & 8 & 8 & 8 & 8 & 8 & 8 \\
\hline $9+$ & $9+$ & $9+$ & $9+$ & $9+$ & $9+$ & $9+$ & $9+$ & $9+$ \\
\hline
\end{tabular}




\section{Appendix B: Some Computational Issues}

The sample objective function $f(b)$ considered in (4) consists of 2 parts- a linear and a concave function of $b$. The key question is whether there exists an interior (unique) maximizer. The following proposition provides conditions that guarantee that there will be an interior, and thus unique, solution for each element of $b$, holding other elements constant.

Proposition 1 Let $b_{-j}=\left[b_{1}, \ldots, b_{j-1}, b_{j+1}, \ldots b_{k}\right]$ where $k=\operatorname{dim}(X)$. Holding $b_{-j}$ constant, there is a unique solution $b_{j}$ to $\max _{b} f(b)$ provided the following condition holds

$$
\sum_{\substack{d u r=s \\ t \\ X_{i}^{j}>0}} X_{i}^{j}>\sum_{\substack{d u r=s+1 \\ t+1}} X_{i}^{j}>\sum_{\substack{d u r=s \\ t \\ X_{i}^{j}<0}} X_{i}^{j}
$$

for each $j=1, \ldots, k$.

Proof. Let $a=\sum_{\substack{d u r=s+1 \\ t+1}} X_{i}$ and use $\sum$ as the short-hand for $\sum_{t} d u r=s$.

Holding $b_{-j}$ constant and take the limit of $(4)$ as $b_{j} \rightarrow \infty$, the second term is approximately

$$
\begin{aligned}
& \sum \log \left(1-\Lambda\left(X_{i} b\right)\right) \\
= & \sum-\log \left(1+\exp \left(X_{i} b\right)\right) \\
= & -\sum_{X_{i}^{j}<0} \log \left(1+\exp \left(X_{i}^{-j} b_{-j}+X_{i}^{j} b_{j}\right)\right)-\sum_{X_{i}^{j}=0} \log \left(1+\exp \left(X_{i}^{-j} b_{-j}+X_{i}^{j} b_{j}\right)\right) \\
& -\sum_{X_{i}^{j}>0} \log \left(1+\exp \left(X_{i}^{-j} b_{-j}+X_{i}^{j} b_{j}\right)\right) \\
\approx & 0-\sum_{X_{i}^{j}=0} \log (\text { constant })-\sum_{X_{i}^{j}>0}\left(X_{i}^{j} b_{j}\right) .
\end{aligned}
$$

This suggests that as $b_{j} \rightarrow \infty,(4) \rightarrow-\infty$ if $a^{j}-\sum_{X_{i}^{j}>0} X_{i}^{j}<0$, for $j=1, \ldots k$.

By similar argument, as $b_{j} \rightarrow-\infty,(4) \rightarrow-\infty$ if $a^{j}-\sum_{X_{i}^{j}<0} X_{i}^{j}>0$, for $j=1, \ldots k$.

An important thing about these conditions is that they can be verified directly from data (by each covariate $X^{j}$ ). In practice, violation of these conditions could lead to insensible estimates. Note, however, in principle, the fact that the condition (6) is satisfied for each element of the parameter $b_{j}, j=1, \ldots k$, does not necessarily imply that there exists an interior (unique) vector of $b$ that maximizes $f(b)$. 